\title{
A new oxidation flow reactor for measuring secondary aerosol formation of rapidly changing emission sources
}

\author{
Pauli Simonen $^{1}$, Erkka Saukko ${ }^{1}$, Panu Karjalainen ${ }^{1}$, Hilkka Timonen $^{2}$, Matthew Bloss ${ }^{2}$, Päivi Aakko-Saksa ${ }^{3}$, \\ Topi Rönkkö ${ }^{1}$, Jorma Keskinen ${ }^{1}$, and Miikka Dal Maso ${ }^{1}$ \\ ${ }^{1}$ Aerosol Physics Laboratory, Department of Physics, Tampere University of Technology, \\ P.O. Box 692, 33101 Tampere, Finland \\ ${ }^{2}$ Finnish Meteorological Institute, Atmospheric Composition Research, P.O. Box 503, 00101 Helsinki, Finland \\ ${ }^{3}$ VTT Technical Research Centre of Finland Ltd., P.O. Box 1000, 02044 Espoo, Finland \\ Correspondence to: Pauli Simonen (pauli.simonen@tut.fi)
}

Received: 16 September 2016 - Discussion started: 1 November 2016

Revised: 2 March 2017 - Accepted: 10 March 2017 - Published: 21 April 2017

\begin{abstract}
Oxidation flow reactors (OFRs) or environmental chambers can be used to estimate secondary aerosol formation potential of different emission sources. Emissions from anthropogenic sources, such as vehicles, often vary on short timescales. For example, to identify the vehicle driving conditions that lead to high potential secondary aerosol emissions, rapid oxidation of exhaust is needed. However, the residence times in environmental chambers and in most oxidation flow reactors are too long to study these transient effects ( $\sim 100 \mathrm{~s}$ in flow reactors and several hours in environmental chambers). Here, we present a new oxidation flow reactor, TSAR (TUT Secondary Aerosol Reactor), which has a short residence time ( $\sim 40 \mathrm{~s})$ and near-laminar flow conditions. These improvements are achieved by reducing the reactor radius and volume. This allows studying, for example, the effect of vehicle driving conditions on the secondary aerosol formation potential of the exhaust. We show that the flow pattern in TSAR is nearly laminar and particle losses are negligible. The secondary organic aerosol (SOA) produced in TSAR has a similar mass spectrum to the SOA produced in the state-of-the-art reactor, PAM (potential aerosol mass). Both reactors produce the same amount of mass, but TSAR has a higher time resolution. We also show that TSAR is capable of measuring the secondary aerosol formation potential of a vehicle during a transient driving cycle and that the fast response of TSAR reveals how different driving conditions affect the amount of formed secondary aerosol. Thus, TSAR can be used to study rapidly changing emission sources, especially the vehicular emissions during transient driving.
\end{abstract}

\section{Introduction}

Aerosol particles in the atmosphere affect climate, health and visibility. To reduce these impacts, the sources of aerosol particles have to be resolved. One large but uncertain source of atmospheric aerosol particles is secondary organic aerosol (SOA) formation, which takes place in the atmosphere when particle mass forms as a result of atmospheric oxidation of organic precursor gases. Because the emission of precursor gases and the formation of secondary aerosol mass occur separately, the estimation of SOA sources and their magnitudes is difficult.

The total amount of atmospheric SOA is typically estimated using laboratory data of SOA yields $(Y)$ for known precursors combined with their emission factors and emission profiles (Kanakidou et al., 2005). However, the uncertainty of this method is high. For example, Kanakidou et al. (2005) estimate that approximately $10 \%$ of global SOA is of anthropogenic origin, but measurements by Volkamer et al. (2006) show that the proportion can be as high as $33 \%$. Thus, more accurate estimations are needed to identify the most important SOA sources in order to identify the most efficient methods to decrease the human impact on aerosol loading in the atmosphere.

An alternative and more direct method for characterizing SOA sources was introduced by Kang et al. (2007). Instead of measuring precursor gases and estimating the amount of potential SOA based on their yields, the SOA formation potential of a single emission source can be measured by oxidiz- 
ing the emitted sample and measuring the secondary aerosol mass produced. This method reduces the uncertainty of the SOA emission magnitude, since unknown precursors as well as those whose measurement is difficult are taken into account.

Using this in situ method, the emission oxidation and SOA formation process can be characterized using large environmental chambers, such as the one Platt et al. (2013) used when they measured the SOA potential of a gasoline vehicle. Another alternative is to use an oxidation flow reactor (OFR), in which the sample is oxidized in a similar manner but with higher oxidant concentrations than in large environmental chambers. Such a setup was first introduced by Kang et al. (2007), who also introduced their own oxidation flow reactor, the potential aerosol mass (PAM) chamber, hereafter referred to as PAM. The setup has been used, for example, to estimate the SOA formation potential of in-use vehicle emissions by sampling air from a highway tunnel (Tkacik et al., 2014), to measure the SOA formation from urban ambient air (Ortega et al., 2016) and to measure the SOA formation from ambient pine-forest air (Palm et al., 2016). All these applications show the value of the direct measurement of SOA potential, since the model results either over- or underestimated the SOA formation.

The use of an oxidation flow reactor instead of a large environmental chamber provides multiple advantages: short residence time, higher degree of oxidation and portability (Bruns et al., 2015). The short residence time allows for high-timeresolution measurements of constantly changing situations; for example, the effect of different test parameters on SOA formation can be studied in a shorter time than with environmental chambers. It is also possible to measure SOA formation of a changing emission source in real time because of the short residence time. For example, Karjalainen et al. (2016) measured the time-resolved SOA formation potential of a gasoline vehicle during a transient driving cycle using a PAM reactor. They observed that the secondary aerosol formation potential is highly dependent on the driving conditions. However, the PAM reactor is not ideal for rapidly changing emission sources such as vehicular emissions, since the residence time $(\sim 100 \mathrm{~s})$ is still relatively long and the reactor outputs a distribution of different-aged aerosol (Lambe et al., 2011). This limitation is seen, for example, in Karjalainen et al. (2016), where the cold start of a gasoline engine results in an exponentially decaying wide peak of SOA formed in PAM, whereas the concentration of total hydrocarbons measured from the exhaust shows a much more transient behavior. Thus, the SOA formed in PAM cannot be linked directly to the emissions. To address this limitation, the residence time must be shortened. An ultimate example of a short-residence-time flow reactor is the microsmog chamber (MSC) with a residence time $<10$ s (Keller and Burtscher, 2012). However, Bruns et al. (2015) show that the composition and amount of the SOA produced in MSC usually differs from those of the SOA produced in PAM or

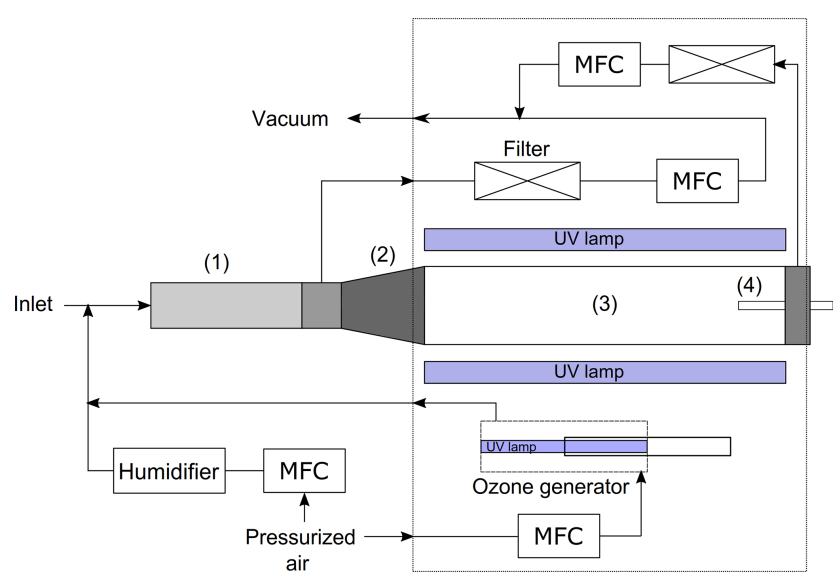

Figure 1. TSAR layout. The residence time chamber (1), the expansion tube (2), the oxidation reactor (3) and the adjustable outlet (4).

in an environmental chamber, possibly because of insufficient time for the condensation of oxidant products. Thus, a compromise between PAM and MSC is needed for studying rapidly changing emissions: shorter residence time than in PAM but still long enough to allow the condensation into the aerosol phase.

In this work, we introduce and present a characterization of a new oxidation flow reactor, the TUT Secondary Aerosol Reactor (TSAR). TSAR is better suited to measuring the realtime secondary aerosol formation potential of rapidly changing emission sources than the state-of-the-art oxidation flow reactors, due to its improved flow conditions and shorter residence time. In the following sections, we characterize TSAR by describing its particle losses, oxidant exposure, residence time distribution and laboratory studies on sulfuric acid yield as well as toluene SOA yield and properties, including a comparison between PAM and TSAR. In addition, we present measurements of the secondary aerosol formation of gasoline vehicle emissions during a transient driving cycle. We show that the fast response of TSAR gives valuable information on the effect of the driving condition on secondary aerosol formation potential.

Because of the high oxidant concentrations, high UV light intensity at non-tropospheric wavelengths and limited time for condensation, atmospheric implications cannot be directly drawn from flow reactor measurements. However, there are no methods to measure the absolute secondary aerosol formation potential, because the environmental chambers also have their drawbacks (e.g., limited oxidant exposure and inability to measure time-resolved secondary aerosol potential; Bruns et al., 2015). Despite these artifacts, there is a need for the estimation of secondary aerosol formation from different emission sources. Thus, the flow reactor results also provide useful information, as long as a proper error analysis is made. In this work, we address the flow re- 
actor related artifacts of TSAR by modeling the vapor losses caused by photolysis and the short residence time.

\section{Experimental}

\subsection{Oxidation flow reactor}

TSAR is an OFR254-type oxidation flow reactor, according to terminology proposed by $\mathrm{Li}$ et al. (2015), which means that $\mathrm{OH}$ radicals are produced from the photolysis of the ozone at $254 \mathrm{~nm}$ UV radiation. Its layout is presented in Fig. 1 (see Fig. S3 in the Supplement for a photograph). TSAR consists of a residence time chamber (1 in Fig. 1), an oxidation reactor (3), an ozone generator, three mass flow controllers and an expansion tube (2) that connects the residence time chamber and oxidation reactor. The residence time chamber is a $50 \mathrm{~cm} \times 5 \mathrm{~cm}$ ID stainless steel cylinder that ensures the mixing of the sample and makes the sample flow laminar before entering the oxidation reactor. The half-cone angle of the expansion tube is $6^{\circ}$. Two of the mass flow controllers are connected to a vacuum line and are used to control the flow rates inside the residence time chamber and the oxidation reactor. The excess flow from the oxidation reactor is hereafter called "secondary excess flow". The third mass flow controller adjusts the air flow through the ozone generator. All the components except the residence time chamber and the expansion tube are located inside a single housing, which makes TSAR easy to transfer to different measuring environments.

The TSAR oxidation reactor is a $3.3 \mathrm{~L}(52 \mathrm{~cm} \times 9 \mathrm{~cm}$ inner diameter) quartz glass cylinder surrounded by two constantpower ozone-free low-pressure mercury lamps which emit $254 \mathrm{~nm}$ UV light. The lamps are placed outside the reactor to ensure laminar flow and to decrease the surface-tovolume ratio. The UV radiation generates excited oxygen atoms $\mathrm{O}\left({ }^{1} \mathrm{D}\right)$ from the photolysis of $\mathrm{O}_{3}$. These atoms react with water molecules, producing $\mathrm{OH}$ radicals. The $\mathrm{O}_{3}$ needed for this reaction chain is mixed with the sample prior to the residence time chamber. In some cases, the humidity of the sample is too low for sufficient $\mathrm{OH}$ generation and additional humidification is required; in these cases, humidified air is also mixed into the sample at this point. If the lamps also emitted $185 \mathrm{~nm}$ UV light, no external ozone generator would be needed and TSAR would operate in OFR185 mode. However, we chose the OFR254 mode because of the poor transmission efficiency of the quartz glass for $185 \mathrm{~nm}$ light. In addition, the $185 \mathrm{~nm}$ light would generate ozone in the room air, which would require special ventilation for the TSAR casing to avoid health issues.

The ozone is generated by an external ozone generator (either model 600 or model 1000, Jelight Company Inc.), which produces ozone from oxygen photolysis by $185 \mathrm{~nm}$ UV radiation. The ozone concentration can be adjusted by partially covering the UV lamp (model 600) or by adjusting the flow rate through the generator.

The TSAR outlet is a $10 \mathrm{~mm}$ OD stainless steel probe, and its axial position can be adjusted so that the oxidized sample can be measured from any distance from the inlet. From the probe, the sample is led to the measurement devices or to an ejector diluter, which allows the use of multiple instruments while maintaining a constant flow through the oxidation reactor.

\subsection{Residence time distribution experiments}

The flow conditions inside the TSAR oxidation reactor affect the dynamic transfer function, $E(t)$, of the reactor for non-reacting compounds. For this case, the measured temporal output concentration, $C_{\text {out }}(t)$, of TSAR for a measured dynamic input concentration, $C_{\mathrm{in}}(t)$, is the convolution of the measured input concentration and the transfer function (Fogler, 2006):

$C_{\text {out }}(t)=E(t) * C_{\text {in }}(t)$.

The transfer function, $E(t)$, is also the unit impulse response of the reactor or the residence time distribution following an ideal Dirac delta input impulse. To test the response function, $10 \mathrm{~s}$ square pulses of $\mathrm{CO}_{2}$ were injected into TSAR mixed with pressurized air. To keep the shape of the $\mathrm{CO}_{2}$ pulse as sharp as possible, the volumetric flow rate in the residence time chamber was kept at $50 \mathrm{slpm}$. In the oxidation reactor the flow rate was $5 \mathrm{slpm} . \mathrm{CO}_{2}$ concentration was measured with a $\mathrm{CO}_{2}$ analyzer (Sidor, Sick Maihak). As the same instrument is used for the measurement of both input and output concentrations, its response function is imbedded both in $C_{\text {in }}(t)$ and $C_{\text {out }}(t)$.

First, three separate $\mathrm{CO}_{2}$ pulses were measured with sampling at the end of the residence time chamber. The outlet probe was then adjusted to sample at the end of the oxidation reactor, and three separate pulses were again measured. The residence time distributions were determined for different situations: UV lamps and the secondary excess flow were either on or off.

\subsection{Particle loss quantification}

Particle losses in the oxidation reactor were measured using dioctyl sebacate (DOS) particles with a mobility diameter from 20 to $100 \mathrm{~nm}$ and silver particles from 5 to $30 \mathrm{~nm}$. The DOS particles were generated by atomizing a DOS-isopropanol solution. The silver particles were generated with an evaporation-condensation technique (Harra et al., 2012). In these experiments, the volumetric flow in both the residence time chamber and oxidation reactor was $5 \mathrm{slpm}$.

A narrow monodisperse particle size distribution, sizeselected using a nanometer differential mobility analyzer (nano-DMA; model 3085, TSI Inc.), was injected into TSAR. The particle number concentration was measured with an ul- 
trafine condensation particle counter (UCPC; model 3025, TSI Inc.) before and after the oxidation reactor using the adjustable outlet probe. This procedure was repeated two or three times for each particle size.

\subsection{OH exposure experiments}

The length of the duration of atmospheric oxidation that the oxidation flow reactor simulates is determined by exposure of the sample to $\mathrm{OH}$ radicals. $\mathrm{OH}$ exposure $\left(\mathrm{OH}_{\text {exp }}\right)$ is defined as $[\mathrm{OH}] \times t$, where $[\mathrm{OH}]$ is the mean $\mathrm{OH}$ radical concentration in the oxidation reactor and $t$ is the mean residence time of the sample in the reactor. $\mathrm{OH}_{\text {exp }}$ could be measured indirectly by monitoring the loss of $\mathrm{SO}_{2}$ in the reactor (Lambe et al., 2011). Since the only significant loss of $\mathrm{SO}_{2}$ in the oxidation reactor is due to the reaction with $\mathrm{OH}$ radicals (and possible wall loss), the change in $\mathrm{SO}_{2}$ concentration is defined by the following differential equation:

$\frac{\mathrm{d}\left[\mathrm{SO}_{2}\right]}{\mathrm{d} t}=-k_{\mathrm{OH}+\mathrm{SO}_{2}}[\mathrm{OH}]\left[\mathrm{SO}_{2}\right]-k_{\mathrm{wall}}\left[\mathrm{SO}_{2}\right]$,

where $\left[\mathrm{SO}_{2}\right]$ is the $\mathrm{SO}_{2}$ concentration, $k_{\mathrm{OH}+\mathrm{SO}_{2}}$ is the reaction rate constant and $k_{\text {wall }}$ is the first-order wall loss for $\mathrm{SO}_{2}$. From this, we get the $\mathrm{OH}$ exposure,

$\mathrm{OH}_{\exp }=\frac{1}{k_{\mathrm{OH}+\mathrm{SO}_{2}}} \ln \frac{\left[\mathrm{SO}_{2}\right]_{0}}{\left[\mathrm{SO}_{2}\right]_{f}}$,

where $\left[\mathrm{SO}_{2}\right]_{0}$ and $\left[\mathrm{SO}_{2}\right]_{f}$ are the $\mathrm{SO}_{2}$ concentrations of the sample before and after oxidation, respectively. Because both $\left[\mathrm{SO}_{2}\right]_{0}$ and $\left[\mathrm{SO}_{2}\right]_{f}$ are measured after TSAR, the first without UV lights and the latter with UV lights, the wall loss term cancels out from the equation.

Because the $\mathrm{OH}$ radicals are produced in a reaction between water molecules and $\mathrm{O}\left({ }^{1} \mathrm{D}\right)$ atoms produced by ozone photolysis, both humidity and ozone concentration affect the amount of OH radicals (Seinfeld and Pandis, 1998). $\mathrm{OH}_{\mathrm{exp}}$ was measured using three different relative humidities $(15$, 30 and $45 \%)$ and several different ozone concentrations (0.6-49 ppm). Humidified air, ozone and $\mathrm{SO}_{2}$ diluted with pressurized air were injected into TSAR to determine the $\mathrm{OH}$ exposure. First, humidity, ozone concentration and $\left[\mathrm{SO}_{2}\right]_{0}$ were measured after TSAR. Then the UV lamps were turned on, and the concentration rapidly decreased and stabilized to the value of $\left[\mathrm{SO}_{2}\right]_{f} . \mathrm{SO}_{2}$ concentration was measured with an AF22M analyzer (Environnement S.A) and ozone with a model 205 analyzer (2B Technologies).

Based on the $\mathrm{OH}_{\exp }$ measurements, it is possible to deduce the UV actinic flux in TSAR by reproducing the results in a photochemical model and using the photon flux as a fitting parameter. We used the model available in the PAM users manual (PAM_chem_v8 by William Brune, https://sites.google.com/site/pamusersmanual/ 7-pam-photochemistry-model/a-introduction), which is similar to the model described by $\mathrm{Li}$ et al. (2015). In this model, the differential equations describing the chemical reactions are solved using Euler's method (instead of the Runge-Kutta method used in the model by Li et al., 2015).

\subsection{Estimating vapor losses and photolysis}

In an ideal oxidation flow reactor, all the condensable vapors condense onto particle phase and will be measured as potential secondary aerosol mass. However, there are also other pathways than condensation for the vapors in the flow reactor, and some of them are non-tropospheric. First, the intensity of the UV radiation is higher and the wavelength is smaller than those of the UV radiation in the troposphere. This can cause unrealistic photolysis of the precursor vapors and the secondary aerosol formed (Peng et al., 2016). Second, the residence time in the flow reactor is small, and thus the condensable vapors may exit the reactor before condensing onto particle phase. Third, because of high oxidant concentrations, the timescale of condensation can be much higher than the timescale of oxidation, leading to fragmentation of oxidized vapor molecules before they have condensed. This is of concern especially in TSAR, where the short residence time requires higher oxidant concentrations than, for example, the PAM chamber. Fourth, the surfacearea-to-volume ratio is high in the flow reactor, and thus the vapor wall losses may be significant (Palm et al., 2016)

\subsubsection{Photolysis}

Peng et al. (2016) have studied the losses of precursor gases and SOA due to photolysis in flow reactors. In their study, they show that the photolysis rate of SOA in oxidation flow reactors is uncertain because of the lack of knowledge on quantum yields. In any case, the loss of SOA due to photolysis is much smaller in oxidation flow reactors than in the troposphere at equivalent $\mathrm{OH}$ exposure. However, the photolytic losses of precursor gases in oxidation flow reactors can be higher than in the troposphere.

The photolytic loss is significant if the photolysis rate is high relative to reaction rate with $\mathrm{OH}$ radicals. We define relative photolytic loss as follows:

relative photolytic loss $=$

$$
\text { photolysis rate at } 254 \mathrm{~nm}
$$

photolysis rate at $254 \mathrm{~nm}+$ reaction rate with $\mathrm{OH}$.

A relative photolytic loss of zero means that all the loss of the precursor gas is due to reaction with $\mathrm{OH}$, and the relative photolytic loss of unity means that the photolysis is the only pathway of loss for the precursor gas. As Peng et al. (2016) show, the relative photolytic loss depends on the ratio of photon exposure to $\mathrm{OH}$ exposure ( $\left.\mathrm{F} 254_{\exp } / \mathrm{OH}_{\exp }\right)$, the reaction rate constant between the precursor molecule and $\mathrm{OH}$ radicals, the absorption cross section of the molecule and the quantum yield of the photolysis reaction. The $\mathrm{OH}$ exposure in TSAR depends on water vapor concentration $\left(\left[\mathrm{H}_{2} \mathrm{O}\right]\right)$, ozone concentration and external $\mathrm{OH}$ reactivity of the sample 
$\left(\mathrm{OHR}_{\mathrm{ext}}=[X] \cdot k_{\mathrm{OH}+X}\right.$, where $[X]$ is the precursor gas concentration and $k_{\mathrm{OH}+X}$ is the reaction rate constant between this gas molecule and $\mathrm{OH}$ radicals). The photon flux in TSAR is constant.

According to the modeling results by Peng et al. (2016), the relative photolytic loss of studied precursor gases is less than $60 \%$ in most cases in OFR254, even at "riskier" conditions $\left(\left[\mathrm{H}_{2} \mathrm{O}\right]<0.1 \%\right.$ or $\left.\mathrm{OHR}_{\text {ext }}>200 \mathrm{~s}^{-1}\right)$. For most of the studied precursor gases, the relative photolytic loss is less than $20 \%$ in most cases. In all the studied "safer" conditions $\left(\left[\mathrm{H}_{2} \mathrm{O}\right]>0.5 \%\right.$ and $\left.\mathrm{OHR}_{\mathrm{ext}}<50 \mathrm{~s}^{-1}\right)$, the relative photolytic loss is less than $30 \%$ for all the precursor gases. However, these are only the upper limits for the relative photolytic losses because of the assumption of a unity quantum yield. The relative photolytic losses in TSAR are discussed in Sect. 3.4.1.

\subsubsection{Vapor losses}

We study the fate of condensable vapors (other than photolysis) in TSAR using a similar approach to Palm et al. (2016). We start with a low-volatility organic compound (LVOC, saturation vapor concentration $\sim 0$ ) which can condense on particle phase, condense on the reactor walls, form new particles via nucleation, react with $\mathrm{OH}$ radicals or exit the reactor before condensing. Thus, the concentration of the LVOC is described with the following differential equation:

$$
\begin{aligned}
\frac{\mathrm{d} C_{0}}{\mathrm{~d} t} & =-4 \pi \cdot D \cdot \mathrm{CS} \cdot C_{0}-k_{\mathrm{w}} \cdot C_{0}-k_{\mathrm{OH}} \cdot C_{0} \cdot[\mathrm{OH}] \\
& -n \cdot J\left(C_{0}\right),
\end{aligned}
$$

where $C_{0}$ is the concentration of the initial LVOC, $D$ is the diffusion coefficient of the LVOC, CS is the condensational $\operatorname{sink}, k_{\mathrm{W}}$ is the first-order rate coefficient for wall loss, $k_{\mathrm{OH}}$ is the reaction rate constant between $\mathrm{OH}$ radicals and the LVOC, $[\mathrm{OH}]$ is the mean concentration of $\mathrm{OH}$ radicals in the reactor, $n$ is the number of molecules in a nucleated particle and $J$ is the nucleation rate, which depends on the vapor concentration. We assume that the reaction with $\mathrm{OH}$ radicals produces another LVOC $\left(C_{1}\right)$ which has the same loss terms as $C_{0}$. Thus,

$$
\begin{aligned}
\frac{\mathrm{d} C_{1}}{\mathrm{~d} t} & =k_{\mathrm{OH}} \cdot C_{0} \cdot[\mathrm{OH}]-4 \pi \cdot D \cdot \mathrm{CS} \cdot C_{1}-k_{\mathrm{w}} \cdot C_{1} \\
& -k_{\mathrm{OH}} \cdot C_{1} \cdot[\mathrm{OH}]-n \cdot J\left(C_{1}\right),
\end{aligned}
$$

and, more generally,

$$
\begin{aligned}
\frac{\mathrm{d} C_{n}}{\mathrm{~d} t} & =k_{\mathrm{OH}} \cdot C_{n-1} \cdot[\mathrm{OH}]-4 \pi \cdot D \cdot \mathrm{CS} \cdot C_{n}-k_{\mathrm{w}} \cdot C_{n} \\
& -k_{\mathrm{OH}} \cdot C_{n} \cdot[\mathrm{OH}]-n \cdot J\left(C_{n}\right),
\end{aligned}
$$

assuming that $k_{\mathrm{OH}}, D, \mathrm{CS}, k_{\mathrm{w}}, n$ and $J$ are equal for all oxidation products.

At some point, the reaction between LVOCs and $\mathrm{OH}$ radicals leads to fragmentation and produces high-volatility compounds which cannot condense onto particle phase. Palm et al. (2016) assumed that the fifth oxidation reaction produces fragmented compounds. In addition, the heterogeneous $\mathrm{OH}$ reaction on the particle surface may result in fragmentation (Kroll et al., 2009). Thus, assuming that the molecule fragments into two parts, we get

$\frac{\mathrm{d} C_{5}}{\mathrm{~d} t}=2 \cdot k_{\mathrm{OH}} \cdot C_{4} \cdot[\mathrm{OH}]+2 \cdot R_{\text {heterogeneous }}$,

where $C_{5}$ is the mass concentration of fragmented, highvolatility compounds and $R_{\text {heterogeneous }}$ is the rate of heterogeneous fragmentation. Based on these equations, the molecule flux to the aerosol phase is

$$
\begin{aligned}
\frac{\mathrm{d} C_{\mathrm{aer}}}{\mathrm{d} t} & =4 \pi \cdot D \cdot \mathrm{CS} \cdot\left(C_{0}+C_{1}+C_{2}+C_{3}+C_{4}\right) \\
& -R_{\text {heterogeneous }},
\end{aligned}
$$

and the mass flux to the reactor walls is

$\frac{\mathrm{d} C_{w}}{\mathrm{~d} t}=k_{\mathrm{w}} \cdot\left(C_{0}+C_{1}+C_{2}+C_{3}+C_{4}\right)$.

The fate of LVOCs is obtained by solving the differential equations using the MATLAB (Release 2016a, The MathWorks, Inc., United States) ode45 numerical solver. The fraction of LVOCs lost to walls is then

$F_{\text {wall }}=\frac{C_{w}\left(\tau_{\text {res }}\right)}{C_{0}(0)}$,

where $\tau_{\text {res }}$ is the residence time of the reactor and $C_{0}(0)$ is the initial LVOC concentration. Similarly, the fraction of LVOCs condensed onto aerosol is

$F_{\mathrm{aer}}=\frac{C_{\mathrm{aer}}\left(\tau_{\mathrm{res}}\right)}{C_{0}(0)}$,

the fragmented fraction is

$F_{\text {frag }}=\frac{1}{2} \frac{C_{5}\left(\tau_{\text {res }}\right)}{C_{0}(0)}$

and, finally, the fraction of LVOCs that exits the reactor before condensing is

$F_{\text {exit }}=\frac{C_{0}\left(\tau_{\text {res }}\right)+C_{1}\left(\tau_{\text {res }}\right)+C_{2}\left(\tau_{\text {res }}\right)+C_{3}\left(\tau_{\text {res }}\right)+C_{4}\left(\tau_{\text {res }}\right)}{C_{0}(0)}$.

Looking at Eqs. (5)-(8), the $\mathrm{OH}$ radical concentration affects the relative amount of LVOCs that is fragmented. The shorter the residence time is, the higher the $[\mathrm{OH}]$ must be to attain a certain $\mathrm{OH}$ exposure. Thus, shortening the residence time results in an increase in fragmented LVOCs. However, the fragmented fraction depends on the timescales of the other loss terms, namely condensation on reactor walls and on aerosol that in turn depends on the condensational sink. Using this approach, the dependence of LVOC fate on residence time and the condensational sink is studied in Sect. 3.4.2. 
We tested the model validity by oxidizing $\mathrm{SO}_{2}$ in TSAR. $\mathrm{SO}_{2}$ oxidation is a simple example of secondary aerosol formation. $\mathrm{SO}_{2}$ reacts with $\mathrm{OH}$ radicals to produce sulfuric acid $\left(\mathrm{H}_{2} \mathrm{SO}_{4}\right)$ vapor which rapidly enters the particle phase by nucleation and condensation (Sihto et al., 2006). The mass formed by oxidation of $\mathrm{SO}_{2}$ can be theoretically calculated from the $\mathrm{SO}_{2}$ loss, and thus comparing the measured mass formation to the theoretical prediction can be used to estimate the capability of TSAR to simulate full atmospheric oxidation. Should the measured mass be substantially smaller than the theoretical, we would assume that there were significant losses of sulfuric acid vapor inside TSAR. The observed losses can then be compared to the losses predicted by Eqs. (11)-(14).

The sulfuric acid yield was measured by injecting humidified air, ozone and $\mathrm{SO}_{2}$ diluted with pressurized air into TSAR. The relative humidity and $\mathrm{SO}_{2}$ was measured straight after TSAR, whereas ozone concentration and the particle size distribution were measured after an ejector diluter (Dekati Ltd.). The dilution ratio was determined by measuring the sample flow rate and the dilution air flow rate. The particle size distribution was measured with a nanometer scanning mobility particle sizer (nano-SMPS), which is a combination of a nano-DMA (model 3085, TSI Inc.) and a UCPC (model 3025, TSI Inc.).

In addition to sulfuric acid, the measured particles also contain water. The sulfuric acid mass was calculated from Eq. (15) (Lambe et al., 2011):

$m_{\mathrm{H}_{2} \mathrm{SO}_{4}}=\chi_{\mathrm{H}_{2} \mathrm{SO}_{4}} \times V \times \rho$,

where $\chi_{\mathrm{H}_{2} \mathrm{SO}_{4}}$ is the mass fraction of sulfuric acid in the particle phase, $V$ is the volume calculated from the nano-SMPS particle size distribution and $\rho$ is the density of the particle phase. Both the mass fraction and the density were calculated as a function of relative humidity based on Seinfeld and Pandis (1998). In the calculations, relative humidity after the dilution is used, assuming fast equilibration of the sulfuric acid particles.

The theoretical (maximum) sulfuric acid mass was calculated by multiplying the loss of $\mathrm{SO}_{2}$ by the molar mass of a sulfuric acid molecule. Thus, the loss of $1 \mathrm{ppb}$ of $\mathrm{SO}_{2}$ produces $4.03 \mu \mathrm{g} \mathrm{m}^{-3}$ of sulfuric acid aerosol, assuming also that all the sulfuric acid condenses into the particle phase.

\subsection{Organic precursor experiments}

A key application of TSAR is to estimate the amount of secondary aerosol mass formed from engine exhaust emissions, which in turn contains a complex mixture of organic and inorganic gases. Therefore, the $\mathrm{SO}_{2}$ oxidation experiment alone is not a representative example of engine exhaust oxidation, because the oxidation pathways of organic compounds are far more complex. The ability of TSAR to form SOA was verified by measuring the toluene SOA obtained by TSAR and PAM simultaneously. Previous studies have
Table 1. Toluene injection cycles.

\begin{tabular}{ll|rl}
\hline \multicolumn{2}{c|}{ Cycle 1 } & \multicolumn{2}{c}{ Cycle 2 } \\
\hline Time (s) & Injection & Time (s) & Injection \\
\hline 0 & on & 0 & on \\
10 & off & 5 & off \\
20 & on & 45 & on \\
25 & off & 55 & off \\
40 & on & 105 & on \\
50 & off & 115 & off \\
\hline
\end{tabular}

shown that the amount and properties of the SOA produced in PAM are similar to those of the SOA formed in smog chambers (Bruns et al., 2015; Lambe et al., 2015).

The organic precursor gas in this experiment was toluene, because it is present in engine exhaust gas (Peng et al., 2012; Wang et al., 2013). In addition, toluene is globally one of the most emitted anthropogenic SOA precursors (Kanakidou et al., 2005). Gas-phase toluene was produced using a permeation oven with a toluene permeation tube (KIN-TEK Analytical, Inc.), and its output rate $\left(\dot{M}_{\text {toluene }}\right)$ was measured by weighing the change in its mass. The concentration of toluene in the reactors is

$C_{\text {toluene }}=\frac{\dot{M}_{\text {toluene }}}{Q_{\text {tot }}}$,

where $Q_{\text {tot }}$ is the total sample flow through the reactors (10 slpm).

The gas-phase toluene was mixed with ozone and humidified air before it was fed to the TSAR residence time chamber. After the residence time chamber, $5 \mathrm{slpm}$ of the sample was introduced into the TSAR oxidation reactor and $5 \mathrm{slpm}$ to PAM. A four-way valve was installed after the reactors, so that the instruments were sampling from one reactor while the sample from the other reactor was drawn to the vacuum line through a mass flow controller.

PAM was used in OFR185 mode ( $\mathrm{Li}$ et al., 2015), and thus the external ozone generator was switched off when the instruments were sampling from PAM. PAM was operated in OFR185 mode instead of OFR254 mode because the OFR185 mode is used in previous engine exhaust studies (Karjalainen et al., 2016; Timonen et al., 2016; Tkacik et al., 2014). Similar results from the two reactors would then indicate that TSAR operating in OFR254 mode could be used in similar applications as PAM in OFR185 mode. The $\mathrm{OH}_{\text {exp }}$ of the reactors was varied by varying the light intensity in PAM and the amount of injected ozone in TSAR. The PAM $\mathrm{OH}_{\exp }$ as a function of output ozone concentration was measured offline in a similar way as for TSAR (Sect. 2.4) at $28 \%$ relative humidity. The PAM reactor $\mathrm{OH}_{\exp }$ as a function of output ozone concentration is shown in Fig. S1.

The particle size distribution downstream of TSAR and PAM was measured with an SMPS (model 3081 DMA and 
model 3775 CPC, TSI Inc.) and also with an engine exhaust particle sizer (EEPS; TSI Inc.; Johnson et al., 2004) in some experiments. The EEPS sample had to be diluted with a mass flow controller to keep the total flow rate through the chambers at $5 \mathrm{slpm}$. Aerosol chemical composition and size distribution were measured with an SP-AMS (soot particleaerosol mass spectrometer; Onasch et al., 2012). In addition, the ozone concentration (model 205, 2B Technologies) and relative humidity (Hygroclip SC05, Rotronic AG) were measured.

Two different toluene experiments were run: steady-state and pulse experiments. In the steady-state experiments, a constant concentration of toluene was continuously injected into the reactors. Based on these experiments, the toluene SOA yield was determined for both reactors.

The pulse experiments were performed to study the reactors' behavior during rapid changes of toluene concentration. In these experiments, toluene was injected through a threeway solenoid valve to either the reactors or to the excess line. Three different pulse experiments were performed: a single $10 \mathrm{~s}$ pulse and two different cycles with several pulses (cycle 1 and cycle 2). In cycle 1, three toluene pulses were injected with intervals of 10 and $15 \mathrm{~s}$, whereas cycle 2 had intervals of 40 and $50 \mathrm{~s}$. The cycles are described in detail in Table 1.

In both cycles, the total toluene injection time was $25 \mathrm{~s}$; therefore, the total amount of injected toluene was equal. EEPS was used to measure the particle number distribution of produced SOA at a time resolution of $1 \mathrm{~s}$. For the pulse experiments, the flow rate through each reactor was $5 \mathrm{slpm}$. Since PAM is approximately 4 times bigger than TSAR in volume, a $10 \mathrm{slpm}$ flow rate was also used for PAM to compare the reactors at more similar mean-plug-flow residence times. In this case, TSAR was bypassed to keep the total flow at 10 slpm.

The SOA yield $(Y)$ is defined as the produced organic aerosol mass $(\Delta M)$ per reacted precursor mass $(\triangle \mathrm{HC}$; Odum et al., 1996):

$Y=\frac{\Delta M}{\Delta \mathrm{HC}}$

The amount of reacted toluene mass depends on the $\mathrm{OH}_{\text {exp }}$; the change in toluene concentration is defined by a similar differential equation as the change in $\mathrm{SO}_{2}$ concentration (Eq. 2). Thus, the amount of reacted toluene is

$$
\begin{aligned}
\Delta[\text { toluene }] & =[\text { toluene }]_{0}\left(1-\exp \left(-k_{\mathrm{OH}+\text { toluene }}\right.\right. \\
& \times \mathrm{OH} \exp ))
\end{aligned}
$$

where [toluene $]_{0}$ is the initial toluene concentration and $k_{\mathrm{OH}+\text { toluene }}$ is the reaction rate constant between toluene and $\mathrm{OH}$ radicals. A rate constant of $6.18 \times 10^{-12} \mathrm{~cm}^{3} \mathrm{~s}^{-1}$ was used based on the parameters presented by Atkinson (1985).

\subsection{Vehicle exhaust experiments}

The ability of TSAR to produce secondary aerosol mass from engine exhaust emissions was evaluated by sampling the exhaust of a Euro 5 GDI light-duty vehicle during a transient driving cycle (New European Driving Cycle, NEDC) run on a chassis dynamometer. The official cycle begins with a cold engine start but, in this study, the NEDC was run with a warm engine, and this is hereafter called a warm NEDC. Prior to the warm NEDC, the vehicle was run at $80 \mathrm{~km} \mathrm{~h}^{-1}$ for at least $3 \mathrm{~min}$, and the cycle began with an idling engine.

The sampling setup of vehicle exhaust experiments is shown in Fig. S2. The engine exhaust was sampled from the tailpipe using a porous tube diluter (PTD) followed by a short cylindrical residence time chamber with a residence time of $2.9 \mathrm{~s}$. The dilution air temperature was $30^{\circ} \mathrm{C}$, and the dilution ratio was approximately 12 . This dilution setup has been shown to mimic the atmospheric cooling and dilution processes of primary aerosol reasonably well (Keskinen and Rönkkö, 2010; Rönkkö et al., 2006). The exact dilution ratio of the PTD was determined by $\mathrm{CO}_{2}$ measurements from the tailpipe and after the PTD. After the residence time chamber, $3 \mathrm{slpm}$ of humidified air and $3 \mathrm{slpm}$ of ozone were mixed with the sample. At this stage, the dilution ratio was 2.5. Thus, the total dilution ratio before TSAR was approximately 30. The sample from TSAR was drawn through an active carbon ozone scrubber to an ejector diluter (Dekati Ltd.) at $5 \mathrm{slpm}$ flow rate. The total dilution ratio between the tailpipe and instruments was determined by $\mathrm{CO}_{2}$ measurements which were performed during $80 \mathrm{~km} \mathrm{~h}^{-1}$ steady-state driving, when the $\mathrm{CO}_{2}$ concentration in the tailpipe was stable.

The particle size distributions were measured with EEPS, an electrical low-pressure impactor (ELPI+, Dekati Ltd.) and a high-resolution low-pressure cascade impactor (HRLPI; Arffman et al., 2014). $\mathrm{CO}_{2}$ concentration after the tailpipe was measured with the Sick Maihak $\mathrm{CO}_{2}$ analyzer, using a sample drier prior to the analyzer. Relative humidity and sample temperature were measured after TSAR using an RH sensor (HygroClip SC05, Rotronic AG).

The amount of secondary aerosol mass produced in TSAR was determined by subtracting the primary mass from the mass measured when using TSAR. Primary aerosol was measured with the same setup by operating TSAR with UV lamps and the ozone generator turned off. The primary emission was measured during two warm NEDCs.

In this setup, the sample flow from the tailpipe is constant regardless of the exhaust mass flow. To determine the emission factors, the measured concentrations are multiplied with the corresponding exhaust mass flow. 


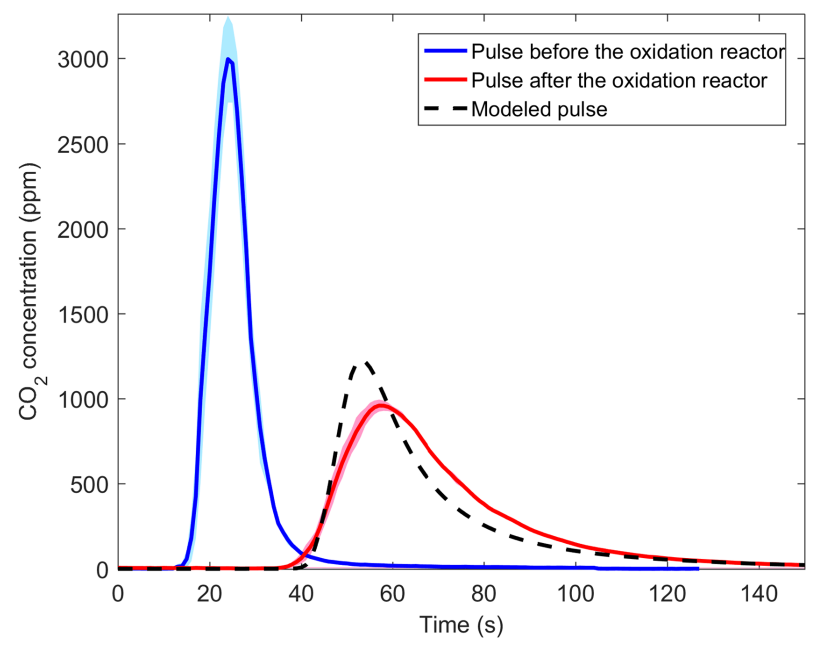

Figure 2. Measured and modeled $\mathrm{CO}_{2}$ pulses before and after the oxidation reactor. The shaded area shows the standard deviation of three pulses. The $\mathrm{CO}_{2}$ background of $380 \mathrm{ppm}$ is subtracted from the results.

\section{Results and discussion}

\subsection{Residence time distribution}

The evolution of a $\mathrm{CO}_{2}$ pulse in TSAR is shown in Fig. 2. A narrow pulse enters the oxidation reactor and exits the reactor as a broader pulse. The theoretical transfer function of the oxidation reactor is calculated based on the residence time distribution of ideal laminar flow:

$E(t)=\left\{\begin{array}{c}0, t<\frac{\tau}{2} \\ \frac{\tau^{2}}{2 t^{3}}, t \geq \frac{\tau}{2}\end{array}\right.$,

where the constant $\tau$ is defined as

$\tau=\frac{\pi R^{2} L}{Q}$,

and $R$ is the inner radius of the reactor, $L$ is the length of the reactor and $Q$ is the flow rate (Fogler, 2006).

Figure 2 shows both the measured pulse after the reactor and the modeled pulse calculated according to Eq. (1) using the theoretical transfer function and the measured input concentration.

As seen in Fig. 2, the measured pulse is somewhat broader than the modeled one. There are some possible reasons for this discrepancy: first, the flow inside the reactor is probably not totally laminar because of the expansion in diameter between the residence time chamber and the oxidation reactor and because of the abrupt diameter change at the end of the reactor; second, the pulse becomes broader in the sampling lines, which is not taken into account here.

In Fig. 2, UV lamps are turned off and the secondary excess flow is on. Because both of these affect the flow, the res-

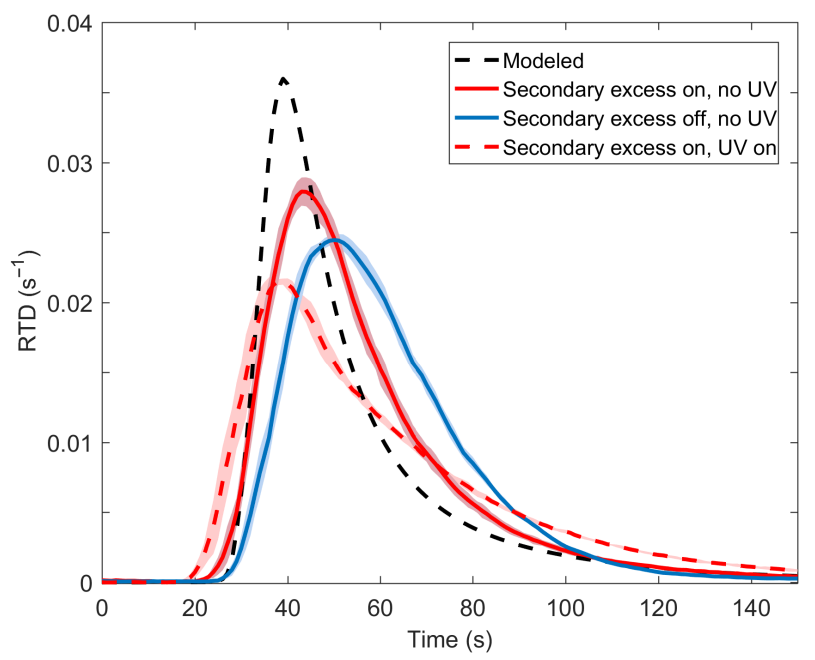

Figure 3. Modeled and measured residence time distributions with and without secondary excess flow and UV lights. The shaded area shows the standard deviation of three pulses.

idence time distribution was measured for different combinations of these parameters, and the results are shown in Fig. 3. In all cases, the total flow rate through the oxidation reactor was $5 \mathrm{slpm}$. Because the incoming pulse is not an ideal Dirac delta function, the residence time distribution cannot be calculated with Eq. (8). Instead, the residence time distribution is the measured concentration, $C_{\text {out }}(t)$, divided by the total area of the pulse (Fogler, 2006):

$\operatorname{RTD}(t)=\frac{C_{\text {out }}(t)}{\int_{0}^{\infty} C_{\text {out }}(t) \mathrm{d} t}$.

Turning off the secondary excess flow broadens the distribution slightly, probably because there is more dead volume at the end of the reactor. Turning the UV lamps on has a similar effect. The UV lamps heat the reactor walls and cause convection inside the reactor. This effect could be reduced by circulating air through the TSAR housing; however, small heating of the reactor walls may decrease the vapor wall losses. Another method to reduce the convection is to place the reactor vertically.

The residence time distributions show that the flow in the TSAR oxidation reactor is near-laminar. Thus, the mean residence time of the sample in the reactor can be calculated with Eq. (22) (Fogler, 2006):

$t_{\text {mean }}=\frac{\tau}{2}=\frac{\pi R^{2} L}{2 Q}$,

which yields $37 \mathrm{~s}$ at $5 \mathrm{slpm}$ flow rate. Turning off the secondary excess flow reduces the laminarity, but this is often necessary to keep the flow rate at $5 \mathrm{slpm}$ since, for example, an ejector diluter alone draws approximately $5 \mathrm{slpm}$ of sample. In any case, the residence time distribution is clearly narrower, and the mean residence time is shorter than those 


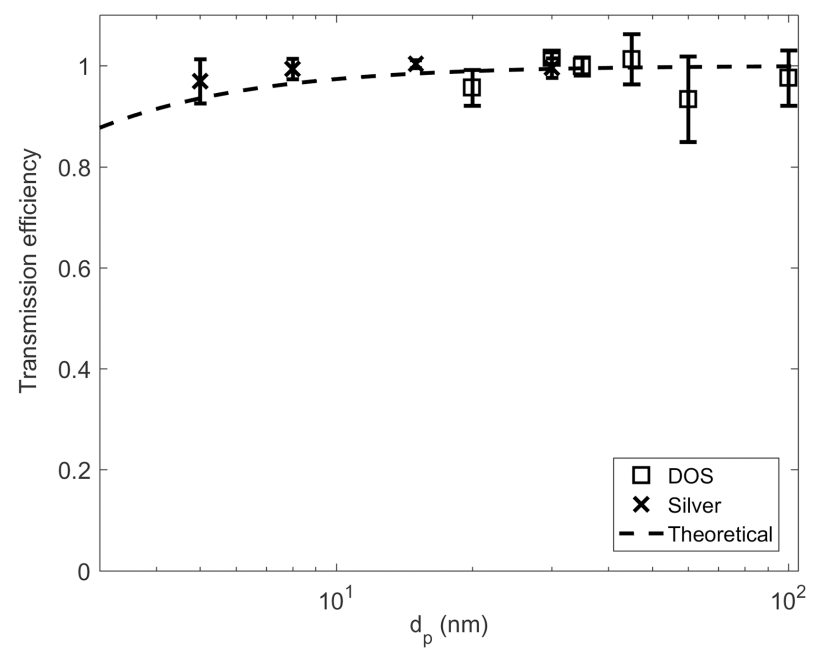

Figure 4. The particle transmission efficiency in the TSAR oxidation reactor. The dashed line shows the theoretical transmission efficiency when the diffusion losses are taken into account. Error bars show the standard deviation.

of PAM (Lambe et al., 2011), allowing the measurement of rapidly changing emission sources.

\subsection{Particle losses}

The particle transmission efficiency as a function of particle mobility diameter is presented in Fig. 4, as well as the theoretical diffusive losses of particles in a tube with laminar flow (Brockmann, 2011). The markers indicate the particle material, and the error bars denote the standard deviation between separate experiments.

Figure 4 shows that the measured transmission efficiency agrees well with the theoretical efficiency, as expected, and thus the losses are less than $10 \%$ when the particle mobility diameter is larger than $5 \mathrm{~nm}$. Therefore, the results in the next sections are not corrected with this efficiency curve because the particle losses are negligible.

According to Lambe et al. (2011), the transmission efficiency of particles is significantly lower in PAM: less than $70 \%$ for particles smaller than $100 \mathrm{~nm}$. Since the flow in TSAR is near-laminar, it is not surprising that the measurements agree with the theory. In PAM, the residence time distribution is broad, allowing more time for the particles to diffuse onto walls (and possibly to coagulate or evaporate), resulting in a non-ideal transmission efficiency.

\subsection{OH exposure}

Figure 5 shows that the $\mathrm{OH}$ exposure in the TSAR oxidation reactor is sensitive to ozone concentration at low concentrations but levels off to a near-constant value when the concentration is higher than $25 \mathrm{ppm}$. The $\mathrm{OH}_{\text {exp }}$ also depends on the relative humidity. The maximum $\mathrm{OH}_{\mathrm{exp}}$ at $30 \%$ $\mathrm{RH}$ is approximately $1.2 \times 10^{12}$ molec s cm $\mathrm{cm}^{-3}$, equivalent to

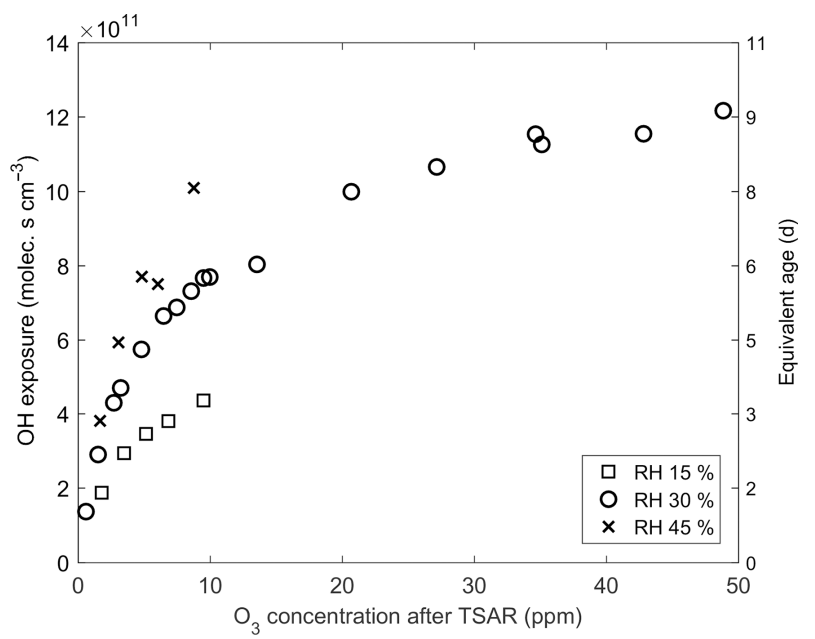

Figure 5. The $\mathrm{OH}$ exposure as a function of $\mathrm{O} 3$ concentration after TSAR.

9 days of atmospheric $\mathrm{OH}$ exposure, whereas in PAM, up to 17 days of equivalent exposure are reached (Lambe et al., 2015; See also Fig. S1). In the calculation of the equivalent atmospheric exposure, an average $\mathrm{OH}$ concentration of $1.5 \times 10^{6}$ molec $\mathrm{cm}^{-3}$ in the atmosphere is assumed (Mao et al., 2009). The TSAR OH exposure could be further increased by increasing the RH or by increasing the UV lamp wattage.

The measurement results could be reproduced in the photochemical model using the photon flux, first-order $\mathrm{OH}$ radical wall loss and first-order ozone wall loss as free parameters. The best fit values are $1.92 \times 10^{15}$ photons $\mathrm{cm}^{-2} \mathrm{~s}^{-1}$ ( $254 \mathrm{~nm}$ photon flux), $8.3 \mathrm{~s}^{-1}$ (OH wall loss) and $7.5 \times$ $10^{-4} \mathrm{~s}^{-1}$ (ozone wall loss). Using these parameters, the model predicts the measurement results within $\pm 20 \%$ uncertainty when the relative humidity, temperature, initial ozone concentration and initial $\mathrm{SO}_{2}$ concentration are used as the input parameters (Fig. S4).

\subsection{Vapor losses and photolysis in TSAR}

\subsubsection{Photolysis}

Based on the modeling results in Sect. 3.3, the flux of $254 \mathrm{~nm}$ photons in TSAR is $1.92 \times 10^{15}$ photons $\mathrm{cm}^{-2} \mathrm{~s}^{-1}$ and does not depend on $\mathrm{OH}$ exposure, since $\mathrm{OH}$ exposure is adjusted by $\mathrm{O}_{3}$ and $\mathrm{H}_{2} \mathrm{O}$ concentration. Assuming a residence time of $37 \mathrm{~s}$ (Sect. 3.1), the ratio F254 exp $/ \mathrm{OH}_{\exp }$ is shown in Fig. 6a. When the $\mathrm{OH}_{\text {exp }}>10^{11}$ molec cm ${ }^{-3} \mathrm{~s}(\sim 0.8$ day equivalent atmospheric exposure), the ratio is less than $10^{6} \mathrm{~cm} \mathrm{~s}^{-1}$. According to Peng et al. (2016), the relative photolytic loss for most VOCs (volatile organic compounds) is below $20 \%$ at this ratio. The only exceptions are acetylacetone, (E,E)-2,4hexadienedial, peroxyacetyl nitrate and species with multiple hydroxyls and carbonyls, whose relative photolytic losses are 30-60\% when $\mathrm{F} 254_{\exp } / \mathrm{OH}_{\exp }$ is $10^{6}$. At higher $\mathrm{OH}_{\exp }$, 

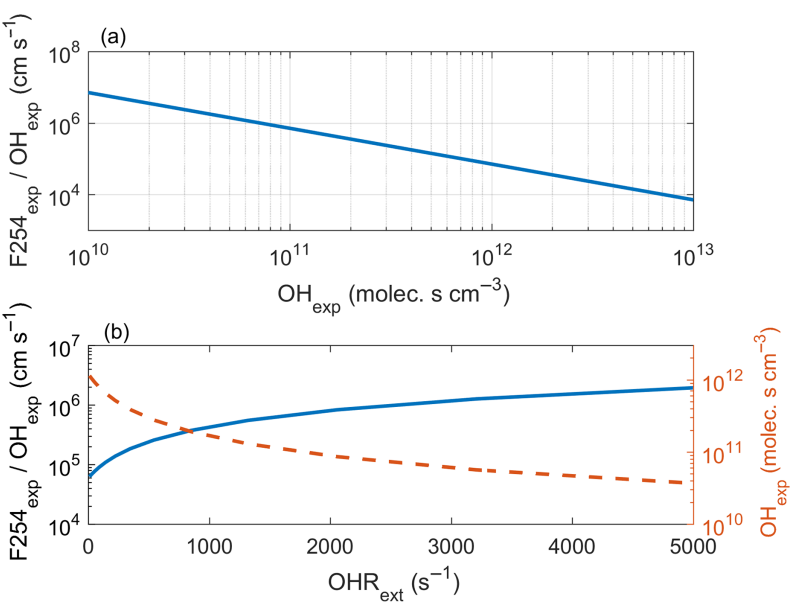

Figure 6. The ratio of $254 \mathrm{~nm}$ photon flux to $\mathrm{OH}$ exposure as a function of $\mathrm{OH}$ exposure (a) and external $\mathrm{OH}$ reactivity, when the initial ozone concentration is $45 \mathrm{ppm}$, relative humidity is $30 \%$ and temperature is $20^{\circ} \mathrm{C}$ (b). In (b), the $\mathrm{OH}$ exposure dependence on $\mathrm{OH}$ reactivity is also shown at same conditions.

the relative photolytic losses decrease. Thus, to avoid nontropospheric photolysis of precursor gases, the $\mathrm{OH}$ exposure must be maintained high enough. However, we note that these relative photolytic losses are upper limits, since a unit quantum yield is assumed in the calculations.

As shown by Peng et al. (2015), the $\mathrm{OH}_{\text {exp }}$ in OFR254 depends on water vapor concentration, $\mathrm{OHR}_{\mathrm{ext}}$, photon flux and ozone concentration. Using the photochemical model described in Sect. 2.4, we evaluate the effect of $\mathrm{OHR}_{\text {ext }}$ on F254 2 exp $/ \mathrm{OH}_{\exp }$ while keeping the temperature, relative humidity and initial ozone concentration constants $\left(20^{\circ} \mathrm{C}, 30 \%\right.$ and $45 \mathrm{ppm}$, respectively). According to the model results (Fig. 6b), F254 exp $/ \mathrm{OH}_{\exp }<10^{6} \mathrm{~cm} \mathrm{~s}^{-1}$ as long as $\mathrm{OHR}_{\text {ext }}$ $<2500 \mathrm{~s}^{-1}$. On the other hand, the $\mathrm{OH}_{\text {exp }}$ decreases as a function of $\mathrm{OHR}_{\text {ext }}$. A worst-case scenario regarding the $\mathrm{OHR}_{\mathrm{ext}}$ in exhaust measurements is a cold engine start, where the $\mathrm{OHR}_{\text {ext }}$ can be as high as 1000-3400 s ${ }^{-1}$ (excluding the effect of $\mathrm{NO}_{x}$ ) when the dilution ratio is $\sim 12$ (Karjalainen et al., 2016; Timonen et al., 2016). The reactions between $\mathrm{NO}_{x}, \mathrm{O}_{3}$ and $\mathrm{OH}$ also decrease the $\mathrm{OH}_{\exp }$ and therefore increase the photolysis rate of VOCs. Thus, a higher dilution ratio than 12 should be used when sampling cold-start engine exhaust into TSAR.

\subsubsection{Vapor losses}

To study the dependence of LVOC fate on residence time and the condensational sink, we define two cases: the oxidation of ambient air (low condensational sink) and diluted vehicle exhaust (high condensational sink). The condensational sink depends on particle number concentration and size and also on the accommodation coefficient $(\alpha)$, diffusion coefficient and molecular mass of the condensing vapor. The first-order rate coefficient for wall loss $\left(k_{\mathrm{w}}\right)$ is calculated as in Palm et al. (2016; see Supplement for details on the calculation of the CS and $k_{\mathrm{w}}$ ). Following the example in Palm et al. (2016), we assume the following properties for the LVOC: molar mass of $200 \mathrm{~g} \mathrm{~mol}^{-1}$, diffusion coefficient $(D)$ of $7 \times 10^{-6} \mathrm{~m}^{2} \mathrm{~s}^{-1}$ and $k_{\mathrm{OH}}=1 \times 10^{-11} \mathrm{~cm}^{3} \mathrm{molec}^{-1} \mathrm{~s}^{-1}$. For simplicity, we assume that the nucleation rate in Eqs. (5)-(7) is zero. Nucleation is still implicitly taken into account because the condensational sink is calculated from the average size distribution before and after TSAR. In addition, we do not consider the heterogeneous fragmentation.

In the case of oxidation of ambient air, the timescale for condensation on aerosol $\tau_{\text {aer }}=(4 \pi \cdot D \cdot \mathrm{CS})^{-1} \approx 65 \mathrm{~s}$ (when $\alpha=1$ ). According to Palm et al. (2016), this is a typical value for ambient pine-forest air oxidized in the PAM chamber when sufficient amounts of precursors are available for SOA formation. This CS is equivalent to that of a log-normal particle size distribution with a total number concentration of $1.5 \times 10^{5} \mathrm{~cm}^{-3}$, median diameter $(\mu)$ of $25 \mathrm{~nm}$ and geometric standard deviation $(\sigma)$ of 1.4. The use of a particle size distribution instead of a constant CS allows us to vary $\alpha$ (since the CS depends on $\alpha$ ). Different values for LVOC mass accommodation coefficients have been proposed. For example, Saleh et al. (2013) measured a value of $\alpha \approx 0.1$ for $\alpha$-Pinene SOA, whereas Palm et al. (2016) argue that $\alpha \approx 1.0$ for ambient pine-forest SOA.

The vapor losses in TSAR for the ambient case as a function of residence time were modeled using the method described in Sect. 2.5.2. Two values of the mass accommodation coefficients were used ( $\alpha=0.1$ and $\alpha=1.0)$. The equivalent $\mathrm{OH}_{\text {exp }}$ is 5 days regardless of the residence time. The results are presented in Fig. 7a. At a typical TSAR residence time (37 s), the LVOC losses in this case are $69-96 \%$, depending on the value of $\alpha$. Most losses are caused by fragmentation, and a longer residence time results in fewer losses (Fig. S5). This is because the shorter the residence time is, the higher the $\mathrm{OH}$ concentration must be to reach the same equivalent $\mathrm{OH}$ exposure. When the $\mathrm{OH}$ concentration is high enough, the timescale of fragmentation is lower than that of condensation.

The vehicle exhaust case is based on the measurements in Sect. 3.6. The mass concentration and $\tau_{\text {aer }}$ of diluted primary aerosol are approximately $4.8 \mu \mathrm{g} \mathrm{m}^{-3}$ and $81 \mathrm{~s}^{-1}$, respectively (when $\alpha=1$ ). This is approximated as a log-normal size distribution with $\mu=31 \mathrm{~nm}, \sigma=1.9$ and a number concentration of $5.4 \times 10^{4} \mathrm{~cm}^{-3}$. According to the measurements in Sect. 3.6, the mass concentration after TSAR is approximately $156 \mathrm{\mu g} \mathrm{m}^{-3}$ (when background is subtracted). For simplicity, we assume that the increase in mass is caused only by condensation, so the number concentration and $\sigma$ are constant. Thus, the size distribution after TSAR is otherwise similar to the primary size distribution, but $\mu=103 \mathrm{~nm}$. The average CS in TSAR is calculated from the average of these two size distributions. 

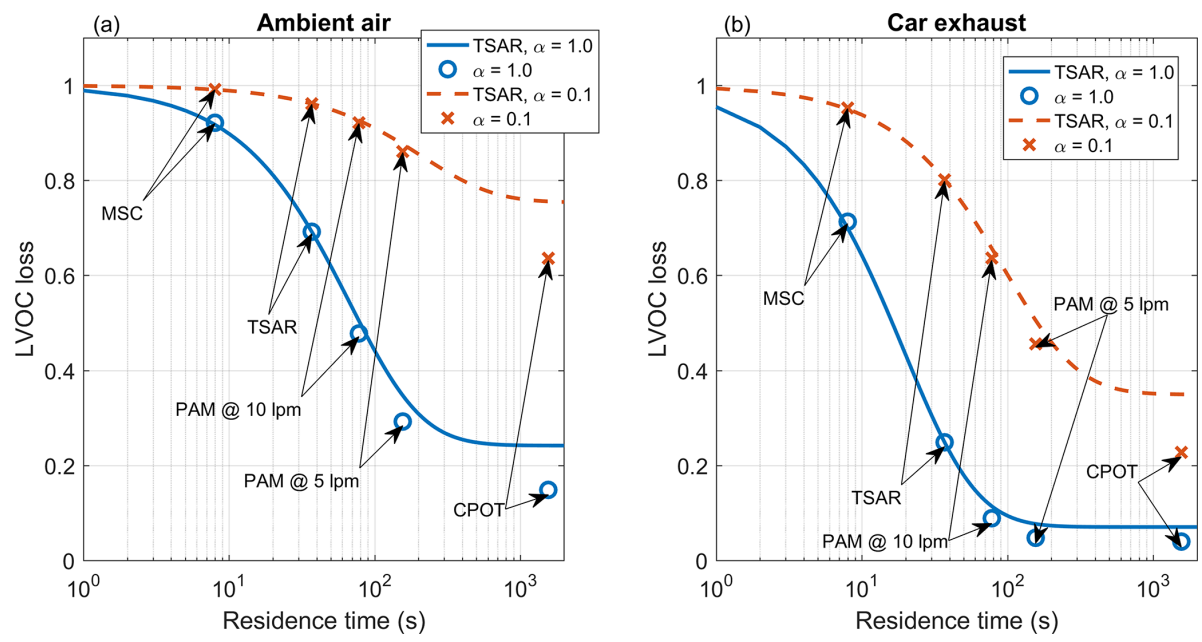

Figure 7. Modeled losses of low-volatility organic compounds as a function of residence time in TSAR in the case of ambient air (a) and vehicle exhaust measurement (b) using two values for the accommodation coefficient $(\alpha)$. The model results for other flow reactors are also shown using typical residence times.

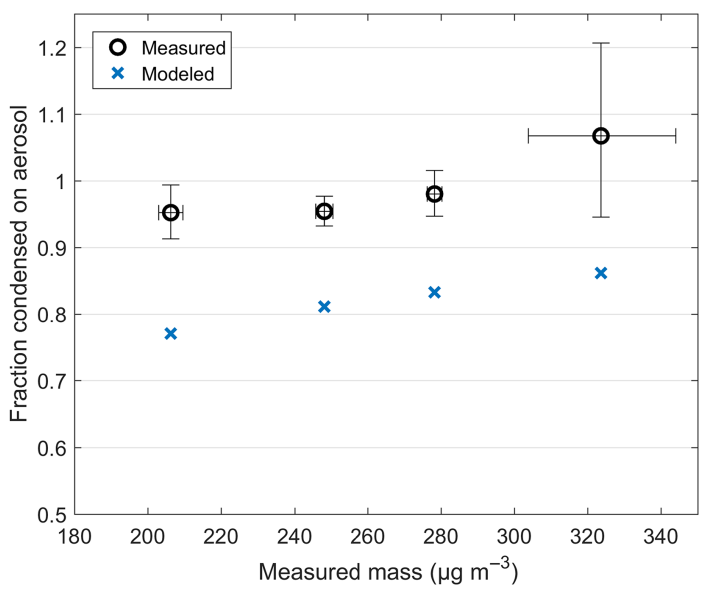

Figure 8. The fraction of the sulfuric acid mass condensed on aerosol phase as a function of measured sulfuric acid mass.

The results for the car exhaust case are presented in Fig. 7b. Now, the LVOC losses in TSAR at typical residence time are 25-80\%, depending on the value of $\alpha$. The losses are lower than in the ambient case because of the shorter timescale of condensation caused by the higher CS. Again, the highest loss is caused by fragmentation (Fig. S5).

In addition to TSAR, we present the estimates for LVOC losses in several other flow reactors, namely MSC, the PAM reactor, and the Caltech Photooxidation Flow Tube reactor (CPOT; Huang et al., 2017) at their typical residence times in Fig. 7. The results differ a little from the TSAR curve because of the different surface-area-to-volume ratios. One must note that the applications of the flow reactors are different; for example, MSC is usually used with a much higher CS than what is modeled here (e.g., Corbin et al., 2015) and, consequently, the losses are smaller than in Fig. 7. Similarly, the main application of TSAR is the engine exhaust measurement, where the CS is usually higher than in ambient air.

The model is tested by comparing the measured and modeled sulfuric acid losses, and the results are shown in Fig. 8. In the model, the following values are assumed for the sulfuric acid molecules: molar mass of $98 \mathrm{~g} \mathrm{~mol}^{-1}, \alpha=0.65$ (Pöschl et al., 1998) and $D=1 \times 10^{-5} \mathrm{~m}^{2} \mathrm{~s}^{-1}$ (Hanson and Eisele, 2000; Palm et al., 2016). We assume there is no fragmentation for sulfuric acid molecules. The CS is again calculated from the average of size distributions after and before TSAR (in this case, the average size distribution is the size distribution measured after TSAR divided by two, since no particles were injected into TSAR). For the three measurements with the smallest error bars, the measured sulfuric acid loss is on average $4 \%$. The modeled loss, in contrast, is $18 \%$ on average. The reason for this discrepancy may be the underestimated CS, since dividing the measured size distribution by two does not necessarily represent the average size distribution in TSAR. If instead the measured size distribution is used for the CS calculation (the upper limit for the average CS), the model results in an average loss of $6 \%$, which is much closer to the measured one and indicates that the nucleated particles already generate a high CS during the first steps of oxidation. Thus, the modeled losses for the ambient and vehicle exhaust case are probably slightly overestimated.

The sulfuric acid experiment shows that the model predicts the losses of a non-fragmenting low-volatility compound reasonably well. However, in Fig. S5 we see that it is the fragmentation that causes the highest losses for LVOCs when the residence time is short $(<50 \mathrm{~s})$. The assumption that the five oxidation steps result in fragmentation is artificial but, if we as a sensitivity test assume that the fragmentation does not occur at all, the change in overall loss is small because a 


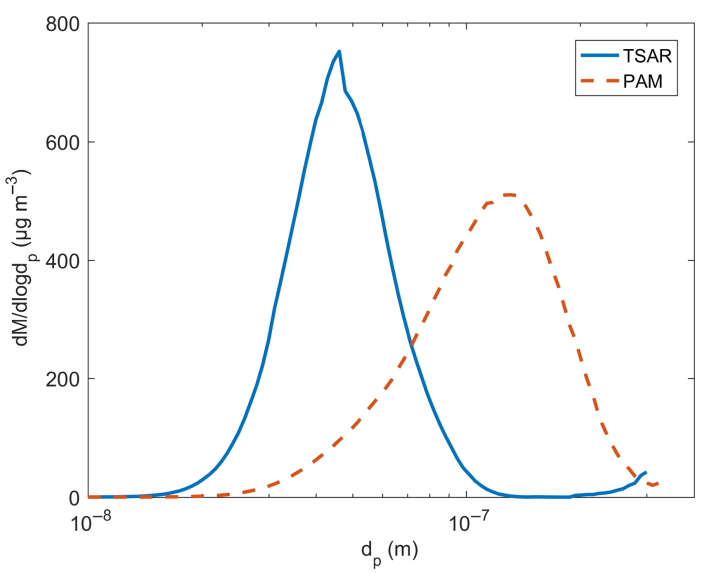

Figure 9. Particle mass size distributions for TSAR- and PAMgenerated toluene SOA, obtained from the SMPS particle number size distribution assuming spherical particles with a density of $1.45 \mathrm{~g} \mathrm{~cm}^{-3}$.

higher proportion of the LVOCs will exit the reactor before condensing (Fig. S6). Still, the losses are a little lower in the case of no fragmentation, and thus more studies on fragmentation are needed to verify the assumptions in the model.

The modeled cases inarguably show that there is a tradeoff between residence time and LVOC losses: the smaller the residence time is, the more losses there are. Thus, the residence time must be chosen according to the application. If a short residence time is used and the CS is low, the injection of seed particles in the sample will reduce the LVOC losses. In the car exhaust case, the CS is high enough for TSAR if the mass accommodation coefficient of the condensing vapor is close to unity. For steady-state experiments, we recommend using a long residence time when there is no need for a fast response. However, even though the LVOC losses are smallest for long-residence-time reactors according to the model results, the particle losses are higher (e.g., $\sim 20 \%$ for PAM and CPOT for $100 \mathrm{~nm}$ particles and $\sim 0 \%$ in TSAR; Huang et al., 2017; Lambe et al., 2011).

\subsection{Toluene SOA yield and properties}

The SOA formation studies were conducted as described in Sect. 2.6. Toluene concentration in the sample entering the reactors was $320 \mathrm{ppb}( \pm 34 \mathrm{ppb})$. During the experiments, the average temperature of the sample was $23.6 \pm 0.2^{\circ} \mathrm{C}$ and the average relative humidity was $31.3 \pm 2.9 \%$, where the uncertainty is the standard deviation of the values.

\subsubsection{Steady-state experiments}

The SOA mass formed in the reactors is calculated from the number size distribution measured by the SMPS, assuming spherical particles with a density of $1.45 \mathrm{~g} \mathrm{~cm}^{-3}$ ( $\mathrm{Ng}$ et al., 2007). The SMPS was used for PM concentration measure-

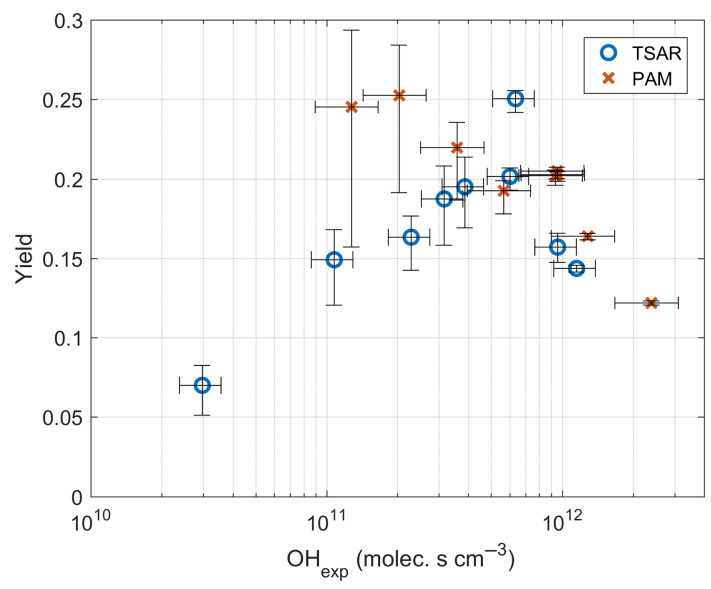

Figure 10. Toluene SOA yield as a function of $\mathrm{OH}$ exposure for both reactors.

ments instead of the AMS because, especially for TSAR, not all particles fall in the AMS detection range $(40-800 \mathrm{~nm})$. The background mass, i.e., the mass formed in the reactors in the absence of toluene, was subtracted from the toluene SOA mass. The background mass consists of oxidation products of the dilution air and depends on the purity of the pressurized air. The purity of the air must always be checked by measuring the mass formed in the flow reactor in the absence of any exhaust or precursors. In this experiment, the background mass concentration was on average $1.2 \mu \mathrm{g} \mathrm{m}^{-3}$ for TSAR and $1.1 \mu \mathrm{g} \mathrm{m}^{-3}$ for PAM. For comparison, the average mass concentration in toluene measurements was $137 \mu \mathrm{g} \mathrm{m}^{-3}$.

Figure 9 shows the SMPS mass distributions of toluene SOA for PAM and TSAR at $\mathrm{OH}_{\exp }$ of $3.6 \times 10^{11}$ and $6.0 \times 10^{11}$ molec $\mathrm{s} \mathrm{cm}^{-3}$, respectively. PAM produces a wide mass distribution where particles above $100 \mathrm{~nm}$ contribute to approximately half of the total mass. TSAR produces a narrower mass distribution where approximately half of the total mass is located in particles smaller than $40 \mathrm{~nm}$. This phenomenon was also reported by Bruns et al. (2015): the micro-smog chamber, which is smaller, has a shorter residence time and generates smaller particles than PAM. As discussed in Sects. 2.5.2 and 3.4.2, the shorter residence time limits the condensational growth of particles and may favor nucleation instead of condensation. Implementing nucleation in the LVOC fate model remains a future task, but an estimation of the losses of toluene oxidation products was conducted in a similar way as in Sect. 3.4.2. If the accommodation coefficient of the oxidation products is one, the LVOC losses for the toluene SOA cases are less than $2 \%$, except for the TSAR measurement at $\mathrm{OH}_{\text {exp }}$ of $3 \times 10^{10} \mathrm{molec} \mathrm{s} \mathrm{cm}^{-3}$, where the losses are approximately $8 \%$. If the accommodation coefficient is 0.1 , the losses are less than $35 \%$, except for the TSAR low- $\mathrm{OH}_{\text {exp }}$ measurement, where the losses are approximately $73 \%$. Since the exact value of the accommo- 


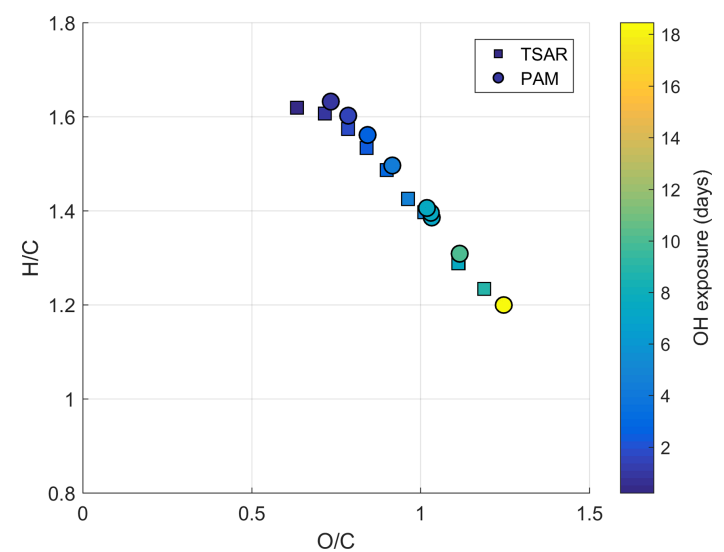

Figure 11. The van Krevelen diagram of toluene SOA for both chambers. The color indicates the $\mathrm{OH}$ exposure.

dation coefficient is unknown, the results in this section are not corrected with the estimated losses.

Figure 10 shows the toluene SOA yield obtained in steadystate experiments as a function of $\mathrm{OH}_{\exp }$ for both reactors. The $\mathrm{OH}_{\text {exp }}$ was not measured simultaneously but is obtained as a function of $\mathrm{O}_{3}$ measured after the reactors from the model described in Sect. 2.4, assuming an $\mathrm{OHR}_{\text {ext }}$ equivalent to $320 \mathrm{ppb}$ of toluene and $\pm 20 \%$ uncertainty in the TSAR $\mathrm{OH}_{\text {exp }}$ and $\pm 30 \%$ in $\mathrm{PAM} \mathrm{OH}_{\text {exp }}$ (PAM model fitting results are presented in Fig. S7). Following the reasoning in Peng et al. (2015), we use $\mathrm{SO}_{2}$ as a proxy for the toluene in the model. The maximum yield is approximately 0.2 for both reactors (neglecting the TSAR outlier at $\mathrm{OH}_{\text {exp }}$ of $6.3 \times$ $10^{11}$ molec s cm${ }^{-3}$ and uncertain PAM values at low $\mathrm{OH}_{\exp }$ ), and both reactors reach the maximum yield at $\mathrm{OH}_{\text {exp }}$ between $0.3 \times 10^{12}$ and $1.0 \times 10^{12}$ molec s cm${ }^{-3}$. Even higher yields are observed in PAM at low $\mathrm{OH}_{\exp }\left(<3 \times 10^{11}\right.$ molec s cm$\left.{ }^{-3}\right)$, but the calculation of yield at this low $\mathrm{OH}_{\text {exp }}$ is very sensitive, because of the small value of the denominator in Eq. (17). This is seen as high uncertainty in PAM yields at low $\mathrm{OH}_{\text {exp }}$. The uncertainty highlights the importance of simultaneous, accurate measurement of $\mathrm{OH}_{\text {exp }}$, especially when the PAM light intensity is low. At higher $\mathrm{OH}_{\text {exp }}$, the yields of the two reactors agree very well.

When the $\mathrm{OH}_{\exp }$ is higher than $1 \times 10^{12}$ molec s cm${ }^{-3}$, the yield starts to decrease in both reactors. This indicates that the assumption on fragmentation in the LVOC loss model (Sect. 2.5.2) is right: the higher the $\mathrm{OH}$ concentration is, the more fragmentation occurs. The fragmented molecules will not condense on aerosol phase; thus, the yield is lower. Still, these results cannot be used to validate the simplified model assumption that the five oxidation steps of an LVOC lead to fragmentation.

The PAM yield in Fig. 10 is not corrected for particle losses, because the losses are characterized only for particles that enter PAM at a certain size and do not grow inside PAM by condensation. This is not the case here, because the
Table 2. Dot product between the organic spectra of PAM- and TSAR-generated SOA.

\begin{tabular}{lrrr}
\hline & \multicolumn{3}{c}{ PAM } \\
\cline { 2 - 4 } TSAR & $\begin{array}{r}\text { Low } \\
\text { oxidation }\end{array}$ & $\begin{array}{r}\text { Medium } \\
\text { oxidation }\end{array}$ & $\begin{array}{r}\text { High } \\
\text { oxidation }\end{array}$ \\
\hline Low oxidation & 0.999 & 0.904 & 0.779 \\
Medium oxidation & 0.904 & 0.999 & 0.978 \\
High oxidation & 0.773 & 0.962 & 0.999 \\
\hline
\end{tabular}

particles are formed via nucleation inside PAM; thus, it is unknown how long they have spent in the reactor and what the particle size as a function of residence time is. As an estimate, the particle size distribution measured after PAM was corrected with the losses measured for this particular chamber (Karjalainen et al., 2016). With this correction, the PAM yield would increase by $19 \%$ on average.

In addition to yield, the chemical composition of produced SOA was studied. In Fig. 11, a van Krevelen diagram shows the oxidation state of SOA for both reactors. In this diagram, the $\mathrm{H} / \mathrm{C}$ ratio is shown as a function of the $\mathrm{O} / \mathrm{C}$ ratio. Elemental ratios are calculated using the method developed by Aiken et al. (2008) and improved by Canagaratna et al. (2015). Oxidation of aerosol usually increases the O / C ratio and decreases the $\mathrm{H} / \mathrm{C}$ ratio (Heald et al., 2010). This phenomenon is observed in both reactors; based on these ratios, the oxidation state of SOA is similar in PAM and TSAR at comparable $\mathrm{OH}$ exposures.

To further compare the SOA oxidation state in the reactors, the average carbon oxidation state $\left(\overline{\mathrm{OS}_{\mathrm{C}}}\right)$ of SOA is shown in Fig. 12. The average carbon oxidation state is a metric which is invariant to hydration or dehydration and is defined as $\overline{\mathrm{OS}_{\mathrm{C}}} \approx 2 \times \mathrm{O} / \mathrm{C}-\mathrm{H} / \mathrm{C}$ (Canagaratna et al., 2015; Kroll et al., 2011). As well as the $\mathrm{O} / \mathrm{C}$ ratios and $\mathrm{H} / \mathrm{C}$ ratios, the $\overline{\mathrm{OS}_{\mathrm{C}}}$ of the SOA in the reactors also agree at comparable $\mathrm{OH}_{\text {exp }}$. The trend of TSAR and PAM $\overline{\mathrm{OS}_{\mathrm{C}}}$ as a function of $\mathrm{OH}_{\text {exp }}$ seems to differ at higher $\mathrm{OH}_{\text {exp }}$, but this can be caused by the uncertainty in the $\mathrm{OH}_{\text {exp }}$ estimation, which is visualized with error bars in Fig. 12.

We also compare the chemical composition of SOA by studying the organic mass spectra. According to Marcolli et al. (2006) and Lambe et al. (2015), a dot product between two normalized mass spectra can be used to determine whether the spectra are similar. The spectra are normalized by dividing each signal by the square root of the sum of the squares of all signals. A dot product of one implies that the spectra are identical and of zero that they are orthogonal.

Toluene SOA here is divided into three categories: low oxidation $\left(-0.18<\overline{\mathrm{OS}_{\mathrm{C}}}<-0.16\right)$, medium oxidation $\left(0.50<\overline{\mathrm{OS}_{\mathrm{C}}}<0.69\right)$ and high oxidation $\left(\overline{\mathrm{OS}_{\mathrm{C}}}>1.10\right)$. The dot products between the organic spectra of different reactors are shown in Table 2. The dot products of normalized mass spectra of SOA produced in reactors at comparable $\overline{\mathrm{OS}_{\mathrm{C}}}$ are 


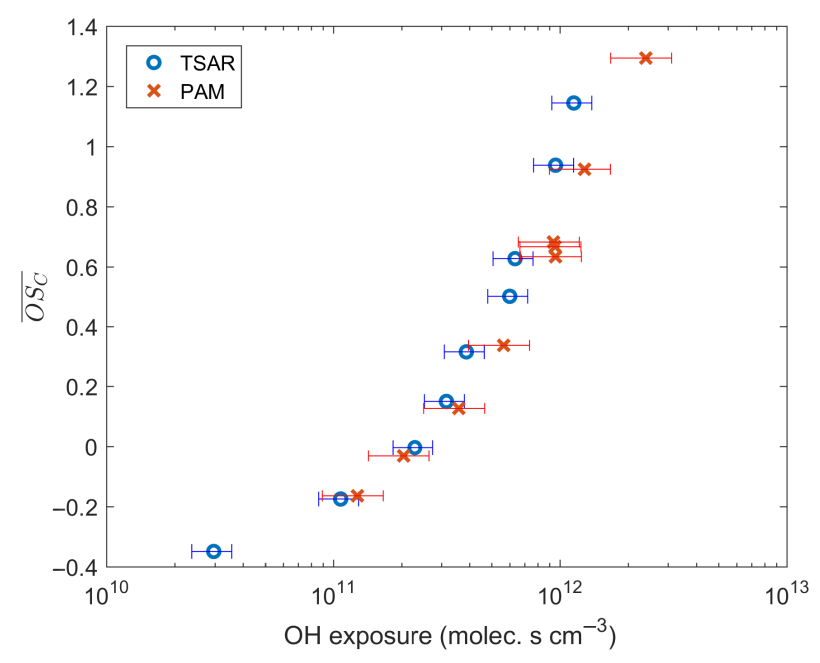

Figure 12. The average carbon oxidation state $\left(\overline{\mathrm{OS}_{\mathrm{C}}}\right)$ as a function of OH exposure for PAM- and TSAR-generated toluene SOA.

above 0.99 , indicating that the reactors produce similar SOA matter in regard to chemical composition.

The TSAR and PAM reactors differ in volume, geometry, flow conditions and residence time. The most significant difference is in the oxidation process: TSAR operates in OFR254 mode and PAM in OFR185 mode. However, the agreement between yields and organic mass spectra of SOA produced in both the TSAR and PAM reactors show that the oxidation products are similar in both reactors, at least in the case of toluene. In OFR254, the sample is first exposed to ozone (before the oxidation reactor) and then to both ozone and $\mathrm{OH}$ radicals. If the VOCs in the sample react fast with ozone, the resulting SOA mass might differ between OFR254 and OFR185. This was not the case for toluene, as dark experiments (only ozone and no UV light) did not produce any secondary mass. In other applications, for example when oxidizing biogenic precursors which are highly reactive towards ozone, the results between OFR254 and OFR185 presumably differ, with OFR 185 being more realistic as the sample is exposed to ozone and $\mathrm{OH}$ simultaneously. However, the main application of TSAR is to measure vehicle emissions, which are more reactive towards $\mathrm{OH}$ than ozone (Gentner et al., 2012; Tkacik et al., 2014). The potential of ozone to produce SOA from the emission can be measured by injecting ozone into TSAR with UV lights turned off.

\subsubsection{Pulse experiments}

The SOA mass concentrations as a function of time are shown in Fig. 13 for all pulse experiments. The $10 \mathrm{~s}$ pulse of toluene results in a sharp peak in mass in TSAR, whereas the PAM reactor produces significantly broader peaks at both used flow rates. Interestingly, the TSAR mass peak is divided into two distinct peaks. We do not know the reason for this phenomenon since the residence time distributions in
Sect. 3.1 do not support this kind of behavior. However, the flow conditions in this experiment are not exactly the same as in Sect. 3.1; here, the flow rate in the residence time chamber is only $10 \mathrm{slpm}$, whereas in Sect. 3.1 it was $50 \mathrm{slpm}$.

Cycle 1 with three rapid toluene pulses shows the importance of laminar flow and short residence time in TSAR: PAM produces only one broad peak whereas all three pulses can be distinguished in the SOA mass produced by TSAR. In cycle 2, where toluene pulses are injected between longer intervals, the pulses are also separated in the mass produced by PAM.

As the total amount of toluene injected into the reactors is known and the yield is determined in Sect. 3.5.1, the total mass produced in the reactors can be predicted with Eq. (23).

$M_{\text {predicted }}=M_{\mathrm{tol}} \times Y$,

where $M_{\mathrm{tol}}$ is the total mass of the toluene injected and $Y$ is the yield. In these experiments, the $\mathrm{OH}_{\exp }$ was approximately $6.1 \times 10^{11}$ in TSAR and $8.3 \times 10^{11}$ molec s cm${ }^{-3}$ in PAM, so a yield of 0.2 is used for both reactors to calculate the expected mass. The mass produced in the reactors is the area of the peaks in Fig. 13 multiplied by the flow rate through the reactors. The comparison between the expected mass and the formed mass is shown in Fig. 14.

In all the experiments, the mass produced in the reactors agrees well with the expected mass. For the $10 \mathrm{~s}$ pulse, PAM mass is lower than the expected mass and the TSAR mass; for cycle 1, TSAR produces more mass than expected; and for cycle 2, both reactors produce less mass than predicted. Considering the uncertainties in this experiment, namely the dilution ratio, EEPS inversion and toluene concentration, we conclude there are no significant differences in the total mass the reactors produce, even though the pulse shapes are clearly different. In all the cases, the mass produced in PAM is slightly lower than in TSAR, probably because the particle losses in PAM are higher.

The agreement between the predicted mass and the produced mass suggests that the approach to measure the secondary aerosol formation potential in real time is valid: the narrow residence time distribution of TSAR gives timeresolved information of SOA formation from fast changing precursor concentrations but still produces approximately the same amount of mass as the PAM reactor, where the oxidation process is slower. Based on these results and the LVOC loss estimation in Sect. 3.4.2, this holds when the condensational sink is high enough. When the CS is smaller (e.g., in ambient air measurements), we expect TSAR to produce less mass than PAM due to the higher losses.

\subsection{Engine exhaust oxidation}

When measuring time-resolved secondary aerosol formation during a transient driving cycle, it is crucial to synchronize real-time aerosol measurements with vehicle speed data. This 

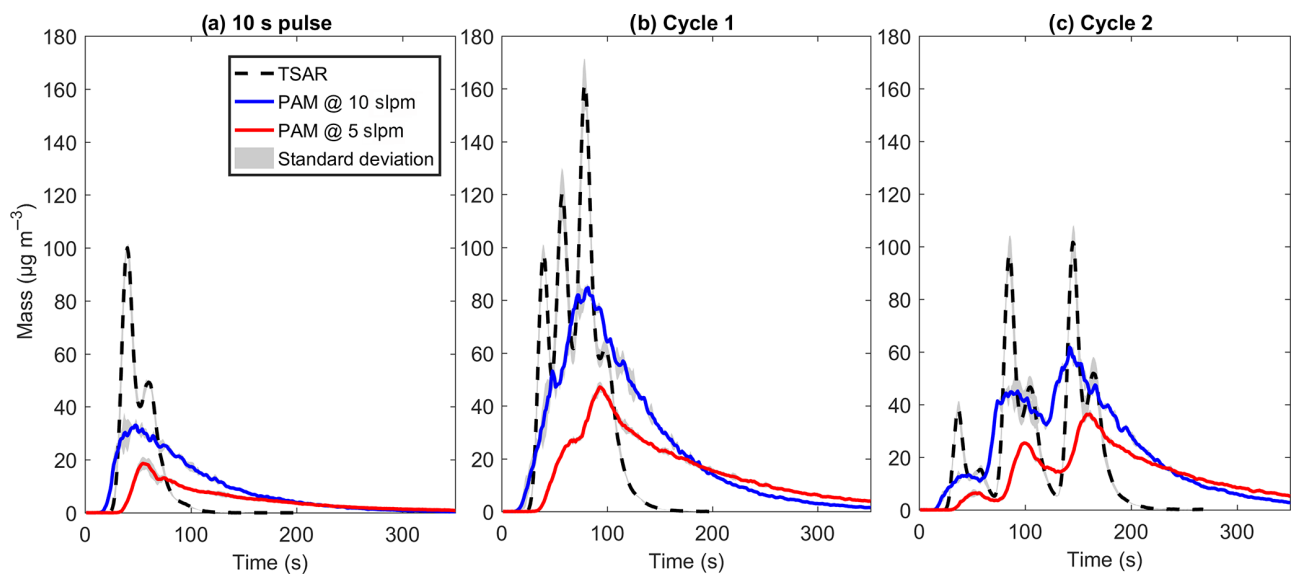

Figure 13. The mass produced from SOA formation of toluene pulses in TSAR at $5 \mathrm{slpm}$ flow rate and in PAM at 5 and 10 slpm flow rates. The shaded area shows the standard deviation. The figures show the mass formation of a single pulse (a) as well as cycle 1 (b) and cycle 2 (c), which are both comprised of three adjacent pulses.

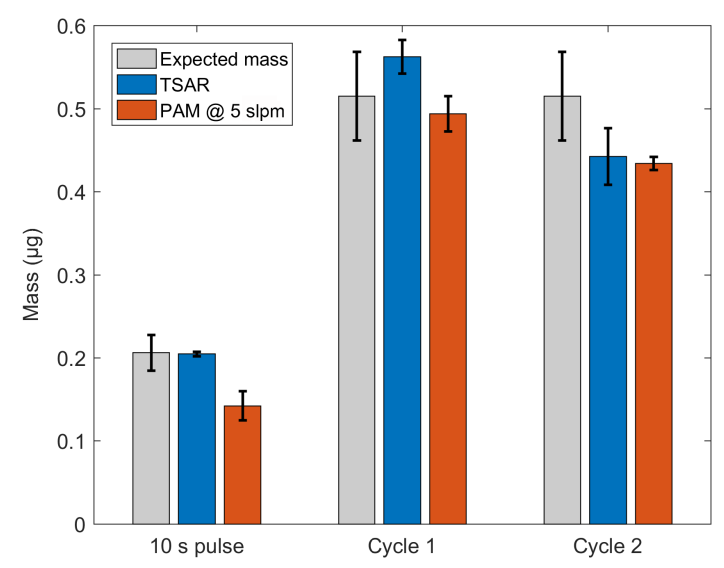

Figure 14. The expected and measured masses produced in pulse experiments. The expected mass is calculated from the mass of injected toluene and its SOA yield.

is performed by comparing the $\mathrm{CO}_{2}$ measurements in the tailpipe and after the dilution steps.

\subsubsection{TSAR oxidation}

In Sect. 3.3 we showed that the $\mathrm{OH}_{\text {exp }}$ in TSAR depends on relative humidity and ozone concentration. In engine exhaust experiments, $\mathrm{RH}$ was $33-36 \%$ and temperature was $22^{\circ} \mathrm{C}$. Ozone concentration was not measured but, based on later laboratory experiments, the ozone concentration was approximately $11 \mathrm{ppm}$ in the sample flow. According to the results presented in Sect. 3.3, the $\mathrm{OH}_{\exp }$ with this ozone concentration is approximately $8 \times 10^{11}$ molec s cm$~^{-3}$ (equivalent photochemical age of 6.3 days). However, this should only be considered as an upper limit for the $\mathrm{OH}_{\text {exp }}$. There is always $\mathrm{NO}$ present in the exhaust sample, and the ozone reacts fast with $\mathrm{NO}$, titrating practically all $\mathrm{NO}$ to $\mathrm{NO}_{2}$ before the sample enters TSAR. Therefore, NO emissions cause a loss in ozone concentration, suppressing the $\mathrm{OH}_{\text {exp }}$. In addition, $\mathrm{NO}_{2}$ and other $\mathrm{OH}$ reactive compounds in the exhaust further decrease the $\mathrm{OH}_{\exp }$. As the concentrations of $\mathrm{NO}_{x}$ and other gaseous compounds vary during the driving cycle, so does the $\mathrm{OH}_{\text {exp }}$. The time-resolved $\mathrm{OH}_{\text {exp }}$ during the driving cycle should be determined by monitoring an $\mathrm{OH}$ reactive tracer, such as $\mathrm{CO}$. In this work, the $\mathrm{OH}_{\exp }$ was not measured in real time.

\subsubsection{Time-resolved secondary aerosol formation}

The secondary aerosol mass concentration formed from the GDI exhaust during a warm NEDC is shown in Fig. 15c. Mass concentration is calculated from the particle number size distribution measured by EEPS assuming spherical particles with a density of $1.0 \mathrm{~g} \mathrm{~cm}^{-3}$ and multiplying the result by the total dilution ratio. The shown mass concentration is an average value of two identical warm NEDCs, and the standard deviation between these two measurements is shown as the shaded area. A constant value of background mass formed from dilution air has been subtracted from the calculated mass. Because of the background mass, the vapor losses here are lower than those modeled in Sect. 3.4.2, at less than $2 \%$ if the accommodation coefficient is 1.0.

Figure $15 \mathrm{c}$ shows significant differences in secondary aerosol formation during different driving conditions. The small standard deviation suggests that the operation of TSAR and the phenomena causing secondary aerosol formation are highly reproducible. The least secondary aerosol formation occurs during long steady-state driving, such as at $70 \mathrm{~km} \mathrm{~h}^{-1}$ at the end of the cycle. When the car is accelerated to 100 and $120 \mathrm{~km} \mathrm{~h}^{-1}$ at the end of the cycle, the secondary aerosol mass formation increases. During most of the cycle, the secondary mass concentration in TSAR is 10-100 times the primary mass concentration (Fig. 15b). However, the difference 

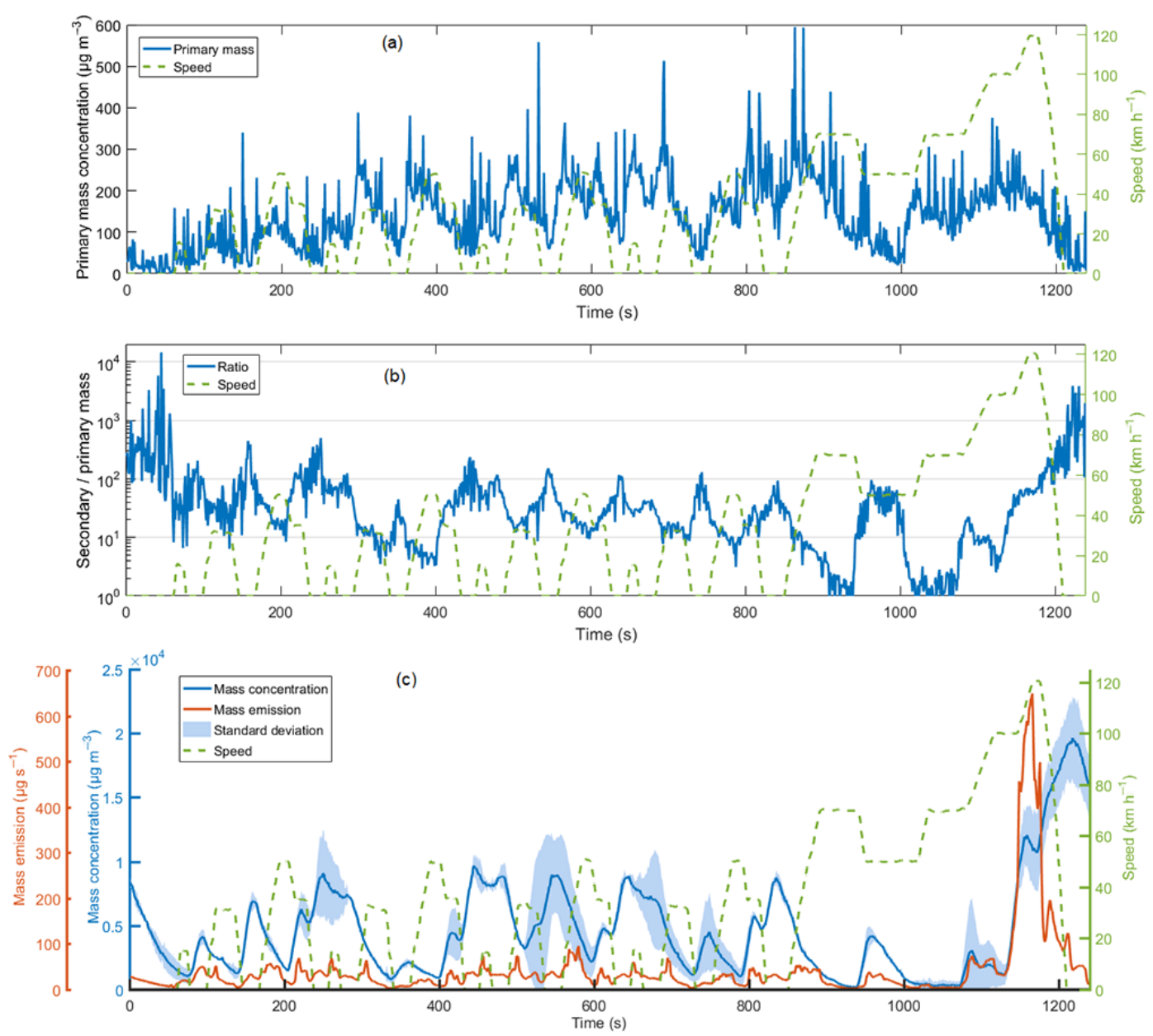

Figure 15. Time series of the vehicle speed and primary mass concentration (a), speed and the secondary-to-primary mass ratio (b), speed, the secondary mass concentration $\left(\mu \mathrm{g} \mathrm{m}^{-3}\right)$ and the secondary mass emission factor $\left(\mu \mathrm{g} \mathrm{s}^{-1}\right)(\mathbf{c})$ during the NEDC. The emission factor is obtained by multiplying the mass concentration by the total volumetric flow of the exhaust.

between primary and secondary emission factors is not that high.

The time-resolved emission factor of secondary aerosol mass in Fig. 15c is achieved by multiplying the secondary mass concentration by the exhaust mass flow. Low exhaust mass flow during engine braking cancels out the high mass concentration peaks. Instead, the peak at the end of the cycle dominates the emissions of secondary aerosol precursors. The total emission factor over the cycle is the integral of the time-resolved emission factor over the cycle length divided by the total distance. For the primary emissions, the emission factor is $0.1 \mathrm{mg} \mathrm{km}^{-1}$, and for the secondary aerosol potential it is 25 times higher at $2.7 \mathrm{mg} \mathrm{km}^{-1}$.

The secondary aerosol emission factors for a similar vehicle and driving cycle reported by Karjalainen et al. (2016) and Platt et al. (2013) are 4.3 and $12.7 \mathrm{mg} \mathrm{km}^{-1}$ (SOA only), respectively. The values are higher than in this study, possibly because the $\mathrm{OH}$ exposures are different; using a PAM reactor, Tkacik et al. (2014) have shown that the SOA formation from vehicle exhaust depends strongly on the $\mathrm{OH}$ exposure. Another reason for the higher values is probably that both Karjalainen et al. (2016) and Platt et al. (2013) used a coldstart cycle. In Karjalainen et al. (2016), most of the secondary mass is indeed formed at the beginning of the cycle, when the engine and the after-treatment system are cold. Interestingly, Karjalainen et al. (2016) do not observe a similar peak in the secondary mass formation at the end of the cycle as we see in Fig. 15c. However, the gas measurements by Karjalainen et al. (2016) and Platt et al. (2013) show that during the last acceleration in the cycle, there were elevated concentrations of total hydrocarbons and ammonia, which could be potential sources of SOA and ammonium nitrate formation in an oxidation flow reactor.

We also observe a new phenomenon, where engine braking results in high concentrations of secondary aerosol forming precursors. Every deceleration (i.e., engine braking) during the warm NEDC produces a peak in secondary mass concentration. The tail at the beginning of the cycle is also a re- 
sult of engine braking, as steady-state driving at $80 \mathrm{~km} \mathrm{~h}^{-1}$ was always performed before the warm NEDC. This phenomenon is not evident in the results of Karjalainen et al. (2016), since the mass concentration does not seem to correlate with vehicle speed in their study. However, they observe repeated events of nanoparticle growth in PAM during the cycle, which could be related to engine braking. Because of the mixing of the sample inside PAM, it is impossible to link these growth events to certain phases in the driving cycle.

Since no aerosol chemical composition measurements were performed, we cannot specify the amount of organic mass in the formed secondary aerosol; therefore, we do not present the emission factor for the SOA potential of the engine exhaust. In addition, the high background mass (i.e., unclean dilution air) and the lack of real-time $\mathrm{OH}_{\text {exp }}$ measurements make these data qualitative rather than quantitative. However, this experiment shows the feasibility of TSAR for measuring the time-resolved secondary aerosol formation potential of rapidly changing vehicle emissions. This way, we can identify the driving conditions in which most secondary aerosol forming precursors are emitted. If the sample were injected to a smog chamber with a constant dilution ratio and then oxidized, like Platt et al. (2013) did, the precursor pulses emitted during engine braking events would cause an overestimation of total secondary aerosol formation potential.

\section{Conclusions}

In this work, we introduced TSAR, a new short-residencetime oxidation flow reactor for secondary aerosol formation measurements. We studied the performance of the reactor by measuring the sulfuric acid yield, toluene SOA yield and the composition and the secondary aerosol formation potential of light-duty gasoline vehicle exhaust during a transient driving cycle. In addition, we characterized the particle transmission efficiency and the residence time distribution of the reactor and did a modeling study on vapor losses in TSAR

According to the model results, the vapor losses in TSAR are higher than in the reactors with longer residence times. The losses depend strongly on the condensational sink of the sample, which is usually high in exhaust measurements (resulting in lower losses). For applications with the low condensational sink, we recommend a longer residence time than in TSAR or the injection of seed aerosol. When there is no possibility for seed aerosol injection, a tradeoff must be made between fast response and low vapor losses.

The toluene experiments show that both the SOA yield and composition are similar in TSAR SOA and PAM SOA, even though PAM operates in OFR185 mode and TSAR in OFR254 mode. The similarity indicates that TSAR can be used instead of the OFR185 PAM reactor when high time resolution is needed.
The particle losses in TSAR are negligible, and the flow is near-laminar. These properties, together with the short residence time, make TSAR better suited for monitoring the secondary aerosol formation potential of rapidly changing emission sources than the PAM chamber. We demonstrate the importance of this feature by measuring the secondary aerosol formation of car exhaust during a driving cycle. This experiment shows that TSAR is able to differentiate which driving conditions are most significant regarding the secondary aerosol formation potential.

Data availability. The data of this study are available from the authors upon request.

\section{The Supplement related to this article is available online at doi:10.5194/amt-10-1519-2017-supplement.}

Competing interests. The authors declare that they have no conflict of interest.

Acknowledgements. TSAR was designed and built in the "FinnishChinese Green ICT R\&D\&I Living Lab for Energy Efficient, Clean and Safe Environments" project and financially supported by the Finnish Funding Agency for Innovation (Tekes), Ahlstrom Oy, FIAC Invest Oy, Green Net Finland Oy, Kauriala Oy, Lassila \& Tikanoja Oyj, Lifa Air Oy, MX Electrix Oy, Pegasor Oy and Sandbox Oy.

The TSAR characterization was conducted in the framework of the HERE project funded by Tekes (the Finnish Funding Agency for Innovation), Agco Power Oy, Dinex Ecocat Oy, Dekati Oy, Neste Oyj, Pegasor Oy and Wärtsilä Finland Oy.

Pauli Simonen acknowledges the Tampere University of Technology Graduate School.

Edited by: Y. Iinuma

Reviewed by: two anonymous referees

\section{References}

Aiken, A. C., DeCarlo, P. F., Kroll, J. H., Worsnop, D. R., Huffman, J. A., Docherty, K. S., Ulbrich, I. M., Mohr, C., Kimmel, J. R., Sueper, D., Sun, Y., Zhang, Q., Trimborn, A., Northway, M., Ziemann, P. J., Canagaratna, M. R., Onasch, T. B., Alfarra, M. R., Prevot, A. S. H., Dommen, J., Duplissy, J., Metzger, A., Baltensperger, U., and Jimenez, J. L.: O / C and OM/OC Ratios of Primary, Secondary, and Ambient Organic Aerosols with HighResolution Time-of-Flight Aerosol Mass Spectrometry, Environ. Sci. Technol., 42, 4478-4485, doi:10.1021/es703009q, 2008.

Arffman, A., Yli-Ojanperä, J., Kalliokoski, J., Harra, J., Pirjola, L., Karjalainen, P., Rönkkö, T., and Keskinen, J.: High-resolution low-pressure cascade impactor, J. Aerosol Sci., 78, 97-109, doi:10.1016/j.jaerosci.2014.08.006, 2014. 
Atkinson, R.: Kinetics and mechanisms of the gas-phase reactions of the hydroxyl radical with organic compounds under atmospheric conditions, Chem. Rev., 85, 69-201, doi:10.1021/cr00071a004, 1985.

Brockmann, J. E.: Aerosol Transport in Sampling Lines and Inlets, in Aerosol Measurement - Principles, Techniques and Applications, edited by: Kulkarni, P. and Baron, P. A., John Wiley \& Sons, Inc., New Jersey, 2011.

Bruns, E. A., El Haddad, I., Keller, A., Klein, F., Kumar, N. K., Pieber, S. M., Corbin, J. C., Slowik, J. G., Brune, W. H., Baltensperger, U., and Prévôt, A. S. H.: Inter-comparison of laboratory smog chamber and flow reactor systems on organic aerosol yield and composition, Atmos. Meas. Tech., 8, 23152332, doi:10.5194/amt-8-2315-2015, 2015.

Canagaratna, M. R., Jimenez, J. L., Kroll, J. H., Chen, Q., Kessler, S. H., Massoli, P., Hildebrandt Ruiz, L., Fortner, E., Williams, L. R., Wilson, K. R., Surratt, J. D., Donahue, N. M., Jayne, J. T., and Worsnop, D. R.: Elemental ratio measurements of organic compounds using aerosol mass spectrometry: characterization, improved calibration, and implications, Atmos. Chem. Phys., 15, 253-272, doi:10.5194/acp-15-253-2015, 2015.

Corbin, J. C., Keller, A., Lohmann, U., Burtscher, H., Sierau, B., and Mensah, A. A.: Organic Emissions from a Wood Stove and a Pellet Stove Before and After Simulated Atmospheric Aging, Aerosol Sci. Tech., 49, 1037-1050, doi:10.1080/02786826.2015.1079586, 2015.

Fogler, H. S.: Elements of Chemical Reaction Engineering, Prentice Hall PTR., 2006.

Gentner, D. R., Isaacman, G., Worton, D. R., Chan, A. W. H., Dallmann, T. R., Davis, L., Liu, S., Day, D. A., Russell, L. M., Wilson, K. R., Weber, R., Guha, A., Harley, R. A. and Goldstein, A. H.: Elucidating secondary organic aerosol from diesel and gasoline vehicles through detailed characterization of organic carbon emissions, P. Natl. Acad. Sci. USA, 109, 18318-18323, doi:10.1073/pnas.1212272109, 2012.

Hanson, D. R. and Eisele, F.: Diffusion of H2SO4 in Humidified Nitrogen: Hydrated H2SO4, J. Phys. Chem. A, 104, 1715-1719, doi:10.1021/jp993622j, 2000.

Harra, J., Mäkitalo, J., Siikanen, R., Virkki, M., Genty, G., Kobayashi, T., Kauranen, M., and Mäkelä, J. M.: Size-controlled aerosol synthesis of silver nanoparticles for plasmonic materials, J. Nanoparticle Res., 14, 870, doi:10.1007/s11051-012-0870-0, 2012.

Heald, C. L., Kroll, J. H., Jimenez, J. L., Docherty, K. S., Decarlo, P. F., Aiken, A. C., Chen, Q., Martin, S. T., Farmer, D. K., and Artaxo, P.: A simplified description of the evolution of organic aerosol composition in the atmosphere, Geophys. Res. Lett., 37, L08803, doi:10.1029/2010GL042737, 2010.

Huang, Y., Coggon, M. M., Zhao, R., Lignell, H., Bauer, M. U., Flagan, R. C., and Seinfeld, J. H.: The Caltech Photooxidation Flow Tube reactor: design, fluid dynamics and characterization, Atmos. Meas. Tech., 10, 839-867, doi:10.5194/amt-10-839-2017, 2017.

Johnson, T., Caldow, R., Pocher, A., Mirmem, A., and Kittelson, D.: A New Electrical Mobility Particle Sizer Spectrometer for Engine Exhaust Particle Measurements, in SAE paper, 2004-0113, 2004.

Kanakidou, M., Seinfeld, J. H., Pandis, S. N., Barnes, I., Dentener, F. J., Facchini, M. C., Van Dingenen, R., Ervens, B., Nenes, A.,
Nielsen, C. J., Swietlicki, E., Putaud, J. P., Balkanski, Y., Fuzzi, S., Horth, J., Moortgat, G. K., Winterhalter, R., Myhre, C. E. L., Tsigaridis, K., Vignati, E., Stephanou, E. G., and Wilson, J.: Organic aerosol and global climate modelling: a review, Atmos. Chem. Phys., 5, 1053-1123, doi:10.5194/acp-5-1053-2005, 2005.

Kang, E., Root, M. J., Toohey, D. W., and Brune, W. H.: Introducing the concept of Potential Aerosol Mass (PAM), Atmos. Chem. Phys., 7, 5727-5744, doi:10.5194/acp-7-5727-2007, 2007.

Karjalainen, P., Timonen, H., Saukko, E., Kuuluvainen, H., Saarikoski, S., Aakko-Saksa, P., Murtonen, T., Bloss, M., Dal Maso, M., Simonen, P., Ahlberg, E., Svenningsson, B., Brune, W. H., Hillamo, R., Keskinen, J., and Rönkkö, T.: Time-resolved characterization of primary particle emissions and secondary particle formation from a modern gasoline passenger car, Atmos. Chem. Phys., 16, 8559-8570, doi:10.5194/acp-16-8559-2016, 2016.

Keller, A. and Burtscher, H.: A continuous photo-oxidation flow reactor for a defined measurement of the SOA formation potential of wood burning emissions, J. Aerosol Sci., 49, 9-20, doi:10.1016/j.jaerosci.2012.02.007, 2012.

Keskinen, J. and Rönkkö, T.: Can real-world diesel exhaust particle size distribution be reproduced in the laboratory? A critical review, J. Air Waste Manage. Assoc., 60, 1245-1255, doi:10.3155/1047-3289.60.10.1245, 2010.

Kroll, J. H., Smith, J. D., Che, D. L., Kessler, S. H., Worsnop, D. R., and Wilson, K. R.: Measurement of fragmentation and functionalization pathways in the heterogeneous oxidation of oxidized organic aerosol, Phys. Chem. Chem. Phys., 11, 8005-8014, doi:10.1039/b916865f, 2009.

Kroll, J. H., Donahue, N. M., Jimenez, J. L., Kessler, S. H., Canagaratna, M. R., Wilson, K. R., Altieri, K. E., Mazzoleni, L. R., Wozniak, A. S., Bluhm, H., Mysak, E. R., Smith, J. D., Kolb, C. E., and Worsnop, D. R.: Carbon oxidation state as a metric for describing the chemistry of atmospheric organic aerosol, Nat. Chem., 3, 133-139, doi:10.1038/nchem.948, 2011.

Lambe, A. T., Ahern, A. T., Williams, L. R., Slowik, J. G., Wong, J. P. S., Abbatt, J. P. D., Brune, W. H., Ng, N. L., Wright, J. P., Croasdale, D. R., Worsnop, D. R., Davidovits, P., and Onasch, T. B.: Characterization of aerosol photooxidation flow reactors: heterogeneous oxidation, secondary organic aerosol formation and cloud condensation nuclei activity measurements, Atmos. Meas. Tech., 4, 445-461, doi:10.5194/amt-4-445-2011, 2011.

Lambe, A. T., Chhabra, P. S., Onasch, T. B., Brune, W. H., Hunter, J. F., Kroll, J. H., Cummings, M. J., Brogan, J. F., Parmar, Y., Worsnop, D. R., Kolb, C. E., and Davidovits, P.: Effect of oxidant concentration, exposure time, and seed particles on secondary organic aerosol chemical composition and yield, Atmos. Chem. Phys., 15, 3063-3075, doi:10.5194/acp-15-3063-2015, 2015.

Li, R., Palm, B. B., Ortega, A. M., Hlywiak, J., Hu, W., Peng, Z., Day, D. A., Knote, C., Brune, W. H., de Gouw, J. A., and Jimenez, J. L.: Modeling the Radical Chemistry in an Oxidation Flow Reactor: Radical Formation and Recycling, Sensitivities, and the $\mathrm{OH}$ Exposure Estimation Equation, J. Phys. Chem. A, 119, 4418-4432, doi:10.1021/jp509534k, 2015.

Mao, J., Ren, X., Brune, W. H., Olson, J. R., Crawford, J. H., Fried, A., Huey, L. G., Cohen, R. C., Heikes, B., Singh, H. B., Blake, D. R., Sachse, G. W., Diskin, G. S., Hall, S. R., and Shetter, R. E.: Airborne measurement of $\mathrm{OH}$ reactivity during INTEX-B, 
Atmos. Chem. Phys., 9, 163-173, doi:10.5194/acp-9-163-2009, 2009.

Marcolli, C., Canagaratna, M. R., Worsnop, D. R., Bahreini, R., de Gouw, J. A., Warneke, C., Goldan, P. D., Kuster, W. C., Williams, E. J., Lerner, B. M., Roberts, J. M., Meagher, J. F., Fehsenfeld, F. C., Marchewka, M., Bertman, S. B., and Middlebrook, A. M.: Cluster Analysis of the Organic Peaks in Bulk Mass Spectra Obtained During the 2002 New England Air Quality Study with an Aerodyne Aerosol Mass Spectrometer, Atmos. Chem. Phys., 6, 5649-5666, doi:10.5194/acp-6-5649-2006, 2006.

Ng, N. L., Kroll, J. H., Chan, A. W. H., Chhabra, P. S., Flagan, R. C., and Seinfeld, J. H.: Secondary organic aerosol formation from m-xylene, toluene, and benzene, Atmos. Chem. Phys., 7, 3909-3922, doi:10.5194/acp-7-3909-2007, 2007.

Odum, J. R., Hoffmann, T., Bowman, F., Collins, D., Flagan, R. C., and Seinfeld, J. H.: Gas/Particle Partitioning and Secondary Organic Aerosol Yields, Environ. Sci. Technol., 30, 2580-2585, doi:10.1021/es950943+, 1996.

Onasch, T. B., Trimborn, a., Fortner, E. C., Jayne, J. T., Kok, G. L., Williams, L. R., Davidovits, P., and Worsnop, D. R.: Soot Particle Aerosol Mass Spectrometer: Development, Validation, and Initial Application, Aerosol Sci. Tech., 46, 804-817, doi:10.1080/02786826.2012.663948, 2012.

Ortega, A. M., Hayes, P. L., Peng, Z., Palm, B. B., Hu, W., Day, D. A., Li, R., Cubison, M. J., Brune, W. H., Graus, M., Warneke, C., Gilman, J. B., Kuster, W. C., de Gouw, J., Gutiérrez-Montes, C., and Jimenez, J. L.: Real-time measurements of secondary organic aerosol formation and aging from ambient air in an oxidation flow reactor in the Los Angeles area, Atmos. Chem. Phys., 16, 7411-7433, doi:10.5194/acp-16-7411-2016, 2016.

Palm, B. B., Campuzano-Jost, P., Ortega, A. M., Day, D. A., Kaser, L., Jud, W., Karl, T., Hansel, A., Hunter, J. F., Cross, E. S., Kroll, J. H., Peng, Z., Brune, W. H., and Jimenez, J. L.: In situ secondary organic aerosol formation from ambient pine forest air using an oxidation flow reactor, Atmos. Chem. Phys., 16, 29432970, doi:10.5194/acp-16-2943-2016, 2016.

Peng, C.-Y., Lan, C.-H., and Yang, C.-Y.: Effects of biodiesel blend fuel on volatile organic compound (VOC) emissions from diesel engine exhaust, Biomass Bioenerg., 36, 96-106, doi:10.1016/j.biombioe.2011.10.016, 2012.

Peng, Z., Day, D. A., Stark, H., Li, R., Lee-Taylor, J., Palm, B. B., Brune, W. H., and Jimenez, J. L.: $\mathrm{HO}_{x}$ radical chemistry in oxidation flow reactors with low-pressure mercury lamps systematically examined by modeling, Atmos. Meas. Tech., 8, 4863-4890, doi:10.5194/amt-8-4863-2015, 2015.

Peng, Z., Day, D. A., Ortega, A. M., Palm, B. B., Hu, W., Stark, H., Li, R., Tsigaridis, K., Brune, W. H., and Jimenez, J. L.: Non-OH chemistry in oxidation flow reactors for the study of atmospheric chemistry systematically examined by modeling, Atmos. Chem. Phys., 16, 4283-4305, doi:10.5194/acp-16-4283-2016, 2016.

Platt, S. M., El Haddad, I., Zardini, A. A., Clairotte, M., Astorga, C., Wolf, R., Slowik, J. G., Temime-Roussel, B., Marchand, N., Ježek, I., Drinovec, L., Mocnik, G., Möhler, O., Richter, R., Barmet, P., Bianchi, F., Baltensperger, U., and Prévôt, A. S. H.: Secondary organic aerosol formation from gasoline vehicle emissions in a new mobile environmental reaction chamber, Atmos. Chem. Phys., 13, 9141-9158, doi:10.5194/acp-13-91412013, 2013.
Pöschl, U., Canagaratna, M., Jayne, J. T., Molina, L. T., Worsnop, D. R., Kolb, C. E., and Molina, M. J.: Mass Accommodation Coefficient of H2SO4 Vapor on Aqueous Sulfuric Acid Surfaces and Gaseous Diffusion Coefficient of $\mathrm{H} 2 \mathrm{SO} 4$ in $\mathrm{N} 2 / \mathrm{H}_{2} \mathrm{O}$, J. Phys. Chem. A, 102, 10082-10089, doi:10.1021/jp982809s, 1998.

Rönkkö, T., Virtanen, A., Vaaraslahti, K., Keskinen, J., Pirjola, L., and Lappi, M.: Effect of dilution conditions and driving parameters on nucleation mode particles in diesel exhaust: Laboratory and on-road study, Atmos. Environ., 40, 2893-2901, doi:10.1016/j.atmosenv.2006.01.002, 2006.

Saleh, R., Donahue, N. M., and Robinson, A. L.: Time Scales for Gas-Particle Partitioning Equilibration of Secondary Organic Aerosol Formed from Alpha-Pinene Ozonolysis, Environ. Sci. Technol., 47, 5588-5594, doi::10.1021/es400078d, 2013.

Seinfeld, J. H. and Pandis, S. N.: Atmospheric chemistry and physics: from air pollution to climate change, Wiley, 1998.

Sihto, S.-L., Kulmala, M., Kerminen, V.-M., Dal Maso, M., Petäjä, T., Riipinen, I., Korhonen, H., Arnold, F., Janson, R., Boy, M., Laaksonen, A., and Lehtinen, K. E. J.: Atmospheric sulphuric acid and aerosol formation: implications from atmospheric measurements for nucleation and early growth mechanisms, Atmos. Chem. Phys., 6, 4079-4091, doi:10.5194/acp-6-4079-2006, 2006.

Timonen, H., Karjalainen, P., Saukko, E., Saarikoski, S., AakkoSaksa, P., Simonen, P., Murtonen, T., Dal Maso, M., Kuuluvainen, H., Ahlberg, E., Svenningsson, B., Pagels, J., Brune, W. H., Keskinen, J., Worsnop, D. R., Hillamo, R., and Rönkkö, T.: Influence of fuel ethanol content on primary emissions and secondary aerosol formation potential for a modern flex-fuel gasoline vehicle, Atmos. Chem. Phys. Discuss., doi:10.5194/acp2016-579, in review, 2016.

Tkacik, D. S., Lambe, A. T., Jathar, S., Li, X., Presto, A. A., Zhao, Y., Blake, D., Meinardi, S., Jayne, J. T., Croteau, P. L., and Robinson, A. L.: Secondary organic aerosol formation from in-use motor vehicle emissions using a potential aerosol mass reactor, Environ. Sci. Technol., 48, 11235-11242, doi:10.1021/es502239v, 2014.

Volkamer, R., Jimenez, J. L., San Martini, F., Dzepina, K., Zhang, Q., Salcedo, D., Molina, L. T., Worsnop, D. R., and Molina, M. J.: Secondary organic aerosol formation from anthropogenic air pollution: Rapid and higher than expected, Geophys. Res. Lett., 33, L17811, doi:10.1029/2006GL026899, 2006.

Wang, J., Jin, L., Gao, J., Shi, J., Zhao, Y., Liu, S., Jin, T., Bai, Z., and $\mathrm{Wu}, \mathrm{C}$. Y.: Investigation of speciated VOC in gasoline vehicular exhaust under ECE and EUDC test cycles, Sci. Total Environ., 445-446, 110-116, doi:10.1016/j.scitotenv.2012.12.044, 2013. 